\title{
Surface Defects as Ingredients that can Improve or Inhibit the Pathways for CO Oxidation at Low Overpotentials Using Pt(111)-type Catalysts
}

\author{
Manuel J. S. Farias*,†, Adilson L. P. Silva§, Auro A. Tanaka ${ }^{\dagger}$, Enrique Herrero ${ }^{\ddagger}$ and Juan M. \\ Feliu ${ }^{\ddagger}$ \\ † Departamento de Química, Universidade Federal do Maranhão, Avenida dos Portugueses, \\ 1966, CEP 65080-805, São Luís (MA), Brazil \\ $\S$ Departamento de Química, Universidade Estadual do Maranhão, Avenida Lourenço Vieira \\ da Silva, 1000, CEP 65055-310, São Luís (MA), Brazil \\ ${ }^{\ddagger}$ Instituto de Electroquímica, Universidad de Alicante, Ap. 99, E-03080, Alicante, Spain
}

\begin{abstract}
All scientific reports regarding the electro-oxidation of $\mathrm{CO}$ on $\mathrm{Pt}$, without exception, show that this reaction is favored on Pt surfaces rich in defects. In fact, "ordinary" or simple CO pre-oxidation is a typical process of surface defected catalysts, obeying the conditions of a full $\mathrm{CO}_{a d s}$ layer formed at suitably low potentials, such as those of the hydrogen under-potential deposition (Hupd) region. Among the $\operatorname{Pt}(111)$-type surfaces, non-defected $\operatorname{Pt}(111)$ has the lowest catalytic activity for $\mathrm{CO}$ electro-oxidation. As a novelty, this paper reports that an unusual CO pre-oxidation appears on a non-defected $\mathrm{Pt}(111)$ surface, depending on the $\mathrm{CO}_{\text {ads }}$ layer preparation, that is, for a $\mathrm{CO}_{\text {ads }}$ layer prepared by cooling the flame annealed $\mathrm{Pt}(111)$ electrode in a $\mathrm{CO}$ atmosphere. The magnitude of this unusual $\mathrm{CO}$ pre-oxidation decreases as the Pt surface becomes rich in steps/defects, and using stepped surfaces, this unusual stage of CO electro-oxidation at low overpotentials is revealed to be connected with long-range order on the (111) plane. Interestingly, both "ordinary" and unusual CO pre-oxidations take place on the (111) terrace domains, but only "ordinary" CO pre-oxidation is favored on surfaces rich in defects. We propose a mechanism of indirect participation of the steps/defects in catalysis, according to which, at low overpotentials, steps/defects on the surface act as ingredients that can improve or inhibit the pathways for the $\mathrm{CO}$ electro-oxidation reaction, but do not serve as the most active sites themselves. Therefore, at least on extended platinum
\end{abstract}


surfaces, there is no general condition whereby surface steps/defects always favor the CO electro-oxidation reaction. From experiments at temperatures ranging from 283 to $313 \mathrm{~K}$, the activation energies for unusual $\mathrm{CO}$ pre-oxidation and the main $\mathrm{CO}$ oxidation processes were about 108 and $117 \mathrm{~kJ} \mathrm{~mol}^{-1}$, respectively. Furthermore, it was found that the increase of the CO stripping temperature caused a proportionally greater reduction of the charge density of the $\mathrm{CO}$ electro-oxidation processes at low overpotentials, that is, the unusual $\mathrm{CO}$ preoxidation, in comparison to the charge density of the oxidation of $\mathrm{CO}$ at the main peak (at higher overpotentials).

Keywords: Electrocatalysis, Pt electrode, CO electro-oxidation, structure-activity correlation, active sites.

*Corresponding Author: manueljsfarias@gmail.com (Manuel J. S. Farias).

Phone: +55 9833018246 . 


\section{Introduction}

Defects, for entropic reasons, are ubiquitous on any real surface ${ }^{1,2}$, and can profoundly impact catalysis on solid surfaces. In fact, defects on the surfaces are typically factors at the molecular scale that can have profound impacts on the catalytic properties, which can be reflected in terms of both catalytic activity and selectivity ${ }^{3}$. In heterogeneous electrocatalysis, reactants (typically a gas or liquid) and the catalyst (the surface of a solid) strongly interact at the electrified interface. This strong catalyst-adsorbate interaction implies that the catalytic performance frequently depends on the arrangement of the atoms at the topmost catalyst surface (and/or sub-surface) ${ }^{4}$. A substantial amount of information is reported in the literature 4, 5 , with trends in the relationship between surface structure and catalytic activity having been observed for catalyzed redox reactions. An important issue of both academic and practical interest concerns the characterization of the roles (or functionalities) that surface defects can eventually play in (some) electro-catalyzed reactions on solid surfaces. The CO electro-oxidation reaction on well-ordered Pt surfaces, because it is a reaction that behaves as sensitive to the surface structure ${ }^{4}$, is a suitable system for the development of this kind of investigation. This reaction is difficult to achieve over platinum, requiring high potentials in the region of $0.7 \mathrm{~V}_{\mathrm{RHE}}$, while the thermodynamics provides a standard potential for the reaction $\mathrm{CO}_{(\mathrm{g})}+\mathrm{H}_{2} \mathrm{O}_{(\mathrm{l})} \rightleftarrows \mathrm{CO}_{2(\mathrm{~g})}+2 \mathrm{H}^{+}+2 \mathrm{e}^{-}$of $-0.104 \mathrm{VsHE}$, so the overpotential is ca. $0.8 \mathrm{~V}$. However, despite this high overpotential, the reaction can occasionally start at low overpotential, in a process known as CO pre-oxidation, which is a characteristic process of defected surfaces ${ }^{6}$ and is related, among other factors (as explained in detail below), to the conditions under which the $\mathrm{CO}_{\text {ads }}$ layer was formed ${ }^{6,7}$. Hence, in the absence of surface defects, the $\mathrm{Pt}(111)$ basal plane is normally very inactive toward the $\mathrm{CO}$ electro-oxidation reaction ${ }^{8}$. We prepared a layer of $\mathrm{CO}_{\text {ads }}$ on non-defected $\mathrm{Pt}(111)$, with this poor catalyst becoming more active than the stepped surfaces based on that basal plane. This broadens the horizon of our understanding of the possible roles (or functionalities) that surface defects can play in the electrocatalysis of $\mathrm{CO}$ oxidation.

Concerning the importance of the steps/defects on the surfaces, it is well documented that the electro-oxidation of $\mathrm{CO}$ is a surface structure sensitive reaction, in which (crystalline ${ }^{9}$ and/or random ${ }^{10-12}$ ) defects on the surface are a beneficial ingredient for achieving high catalytic activities at low overpotentials ${ }^{9-11}$. Studies using stepped Pt surfaces consisting of different width (111) terraces interrupted by (110) monoatomic steps have shown that the CO 
electro-oxidation reaction rate increases with increasing steps density, and that extrapolation of the reaction rate to a surface with zero defect density, equivalent to a perfect $\operatorname{Pt}(111)$ surface, closely corresponds to a negligible reaction rate ${ }^{9}$. Although the reaction rate tends to zero as the steps or defects disappear from the catalyst surface, this trend alone does not reveal the true identity of the active sites or the most active sites involved in the reaction. Using stepped Pt surfaces, and marking specific sites with an isotopically labeled reaction intermediate ${ }^{13}$, the characterization (in two-dimensions) of the most active sites confirmed that the steps/defects can modify the neighboring (111) terraces below the steps/defects, in a process related to the electronic charge separation between the top and bottom of the steps. Under these circumstances, new local conditions emerge in these (111) domains, which can improve or even inhibit specific reaction pathways at these locations. In the specific case of reaction pathways involving the electro-oxidation of $\mathrm{CO}_{\text {ads }}$ on $\mathrm{Pt}(111)$-type stepped surfaces, the modification of (111) domains by steps/defects culminates in the emergence of the very active sites on these "electronically modified" (111) facets ${ }^{13}$. This is the most likely mechanism for indirect participation of the surface steps/defects in catalysis, whose beneficial action favors the electrocatalysis of CO oxidation on the (111) terraces of (extended) Pt surfaces. Therefore, experience has shown that a successful strategy to improve the electrocatalysis of CO oxidation on $\mathrm{Pt}$ is to introduce steps/defects on the catalyst surfaces. This is almost correct, but it does not always work, as will be discussed later ${ }^{14}$. Interestingly, this makes the Pt/CO system very useful for serendipitous discovery, as occurred with the discovery of $\mathrm{CO}$ pre-oxidation ${ }^{15}$.

In $\mathrm{CO}$ stripping experiments, the $\mathrm{CO}$ pre-oxidation can be considered an ignition process that frequently appears as a voltammetric small wave in the early stage, or a preignition of the electro-oxidation reaction of the $\mathrm{CO}_{a d s}$ layer. When the pre-oxidation peak appears, it precedes one or more major oxidation peaks, and it is not difficult to differentiate between one and the other. However, in a quiescent $\mathrm{CO}$ saturated solution, when the $\mathrm{CO}$ preoxidation is present ${ }^{16}$, it can mix with the electro-oxidation of $\mathrm{CO}$ from the solution (also called bulk CO electro-oxidation), so it is not possible to differentiate one process from the other. Hence, it is important to study the $\mathrm{CO}$ pre-oxidation with control of the $\mathrm{CO}$ in the solution (including the absence of $\mathrm{CO}$ in the solution).

In quantitative terms, depending on the orientation of the electrode surface, the charge corresponding to the $\mathrm{CO}$ pre-oxidation process does not exceed around $8 \%$ of the charge for 
electro-oxidation of a complete layer of $\mathrm{CO}_{\text {ads. }}$ Since the $\mathrm{CO}$ pre-oxidation corresponds to a stage of CO electro-oxidation requiring low overpotentials, due to the reaction being surface structure sensitive, it seems logical that it should only involve the most catalytically active sites on a catalyst with heterogeneous surface sites. Hence, it is not plausible that the catalytic process on a surface with heterogeneous sites would start anywhere on the catalyst surface. Consequently, it is necessary to revisit the experimental conditions under which the CO preoxidation very often appears, as well as to examine the characteristics of the possible most active sites involved in the reaction pathways of $\mathrm{CO}$ pre-oxidation. Then, for a $\mathrm{CO}_{\text {ads }}$ layer adsorbed under potential control, the voltammetric evolution of the $\mathrm{CO}$ pre-oxidation requires fulfillment of the following interconnected conditions ${ }^{17}$ : (1) adsorption of $\mathrm{CO}$ at potentials lower than about $0.2 \mathrm{~V}_{\mathrm{RHE}}$; (2) a defected catalyst surface; (3) surfaces saturated with $\mathrm{CO}_{\mathrm{ads}}$; (4) presence of traces of $\mathrm{CO}$ in the solution phase. The appearance of the CO preoxidation process implies that the rate of the $\mathrm{CO}$ electro-oxidation reaction is highly sensitive to conditions that are not related to either the nature of the catalyst or the chemical nature of the electrolyte. The condition of surface $\mathrm{CO}$ saturation implies that all types of Pt sites become occupied by $\mathrm{CO}_{\text {ads, }}$ including the top sites of the steps, their corresponding bottom sites, and terraces. For the process of $\mathrm{CO}_{\text {ads }}$ layer formation on a polycrystalline Pt surface in an acid media, experiments employing slow mass transport ( $\mathrm{CO}$ extremely diluted or titrating $\mathrm{Pt}$ surface with $\mathrm{CO}$ molecules ${ }^{18}$ ), with monitoring of the $\mathrm{CO}$ stretching frequencies of $\mathrm{CO}_{\text {ads }}$ by in situ attenuated total reflectance-surface enhanced IR absorption spectroscopy, showed that CO preferentially occupies sites consisting of low coordinated atoms (defects) ${ }^{18}$. A similar conclusion was reached previously by Cuesta et al. ${ }^{19}$, employing similar spectroscopic techniques. In a previous paper ${ }^{20}$, apparent non-preferential $\mathrm{CO}$ site occupation on $\mathrm{Pt}$ electrodes in an acid media at very early stages in the formation of the $\mathrm{CO}_{\text {ads }}$ layer was possibly wrongly identified, because the $\mathrm{CO}$ gas did not meet the condition of being extremely diluted in the solution. In fact, under this last condition, it seems that there is no preferential CO site occupation (as can be seen in the spectra reported elsewhere ${ }^{19}$ ). Employing stepped Pt surfaces, it was concluded that the set of sites at the bottom side of the steps, which are (111) terrace sites, are the hardest sites to be occupied by $\mathrm{CO}^{21}$. Interestingly, these sites have been identified as those requiring the smallest overpotentials for activation of the pathways for the $\mathrm{CO}$ electro-oxidation reaction ${ }^{21}$. The highest $\mathrm{CO}$ coverages are achieved when the adsorption potentials are as low as those of the HUPD region, and the solution must contain traces of 
dissolved $\mathrm{CO}^{22}$. On $\mathrm{Pt}(111)$ stepped surfaces, since the $\mathrm{CO}$ pre-oxidation involves the sites at the bottom side of the steps, the above consideration can explain why the four aforementioned conditions must be fulfilled to ensure the appearance of the CO pre-oxidation 17.

In CO saturated solution, it has been found that $\mathrm{CO}$ on a $\mathrm{Pt}(111)$-type electrode in an acid solution forms a $\mathrm{CO}_{\text {ads }}$ superstructure, $p(2 \times 2)-3 \mathrm{CO}\left(\theta_{c o}=0.75\right)$, whose phase transitions toward $(\sqrt{19} \times \sqrt{19}) R 23.4^{\circ}-13 \mathrm{CO}\left(\theta_{\mathrm{co}} \simeq 0.68\right)$, by means of transient structures, takes place at potentials at which the $\mathrm{CO}$ pre-oxidation appears ${ }^{23,24}$. The transition between both structures is catalyzed by the presence of steps ${ }^{25}$. The first structure is obtained for a $\mathrm{CO}_{\text {ads }}$ layer obtained at low potentials (such as $\sim 0.0 \mathrm{~V}$ RHE), in the presence of $\mathrm{CO}$ in the solution ${ }^{26}$. The second structure is obtained at a potential of around $\sim 0.5 \mathrm{~V}_{\mathrm{RHE}}{ }^{26}$, apparently even in the absence of $\mathrm{CO}$ in the solution ${ }^{23}$. An additional structure for the $\mathrm{CO}_{\text {ads }}$ layer, the $(\sqrt{7} \times \sqrt{7}) R 19.1^{\circ}-4 \mathrm{CO}$ $(\theta \mathrm{co} \simeq 0.57)$, has also been observed for diluted $\mathrm{CO}_{\text {ads }}$ layers in absence of $\mathrm{CO}$ in the solution phase ${ }^{26}$. The CO pre-oxidation also appears on $\mathrm{Pt}(100)$ surfaces ${ }^{27}$, particularly defected ones ${ }^{28}$, as well as on polycrystalline $\mathrm{Pt}{ }^{29,30}$ and (faceted) Pt nanoparticles ${ }^{31}{ }^{32}$, provided that criterion of the low potentials for $\mathrm{CO}$ adsorption is obeyed, as explained above. On $\mathrm{Pt}(100)$ type surfaces, the $\mathrm{CO}$ pre-oxidation is usually much more pronounced, corresponding to the electro-oxidation of about $15 \%$ of the complete layer of $\mathrm{CO}_{\mathrm{ads}}$, and the pre-oxidation peak and the main oxidation peak appear separated by $\sim 0.25 \mathrm{~V} 28,33$. It should be noted that in alkaline solution, the $\mathrm{CO}$ pre-oxidation appears, irrespective of whether there is a trace of $\mathrm{CO}$ in the solution side ${ }^{21,34}$. Considering CO pre-oxidation only on $\mathrm{Pt}(111)$-type surfaces, the emergence of catalytic activity at low overpotentials is associated with the presence of steps/defects on the surface ${ }^{6,17,23,24,35-37}$ (a certain type of surface defects ${ }^{37}$ ). However, in previous work, it was found that the magnitude of the $\mathrm{CO}$ pre-oxidation was impaired by defects on the surfaces when the $\mathrm{CO}_{\text {ads }}$ layer was formed while the flame annealed $\mathrm{Pt}(111)$ electrode was suitably cooled in a $\mathrm{CO}$ atmosphere ${ }^{14}$. This finding highlights the complexity of the roles that surface defects can play in the electrocatalysis of $\mathrm{CO}$ oxidation and deserve to be investigated.

One aim of the work was to provide further insights concerning the characterization of the role of surface defects in electrocatalysis of the $\mathrm{CO}$ oxidation reaction at low overpotentials, particularly as a result of pretreatment of the catalyst surface. 


\section{Experimental Section}

\subsection{Electrodes and Electrolytes}

Bead-type electrodes (oriented area $\sim 4.5 \mathrm{~mm}^{2}$ ) were used as working electrodes, namely $\operatorname{Pt}(111), \operatorname{Pt}(2020$ 19), $\operatorname{Pt}(1313$ 12), and $\operatorname{Pt}(332)$, which consisted of “infinite", 39, 25, and 5 atom-wide (111) terraces, respectively, periodically broken by (110) monoatomic steps. The oriented surfaces of the last three bead-type electrodes are called stepped surfaces. A very useful way to represent stepped surfaces is to use the Lang-Joyner-Somorjai model ${ }^{38}$, according to which these surfaces belong to the $\operatorname{Pt}(\mathrm{s})-[(n-1)(111) \times(110)]$ series (where $n$ is the number of atoms comprising the width of the (111) terraces). The Miller index for these surfaces is $(n, n, n-2)$ and they can be individually represented as follows:

$$
\begin{gathered}
\operatorname{Pt}(202019) \equiv \operatorname{Pt}(\mathrm{s})-[39(111) \times(110)], n-1=39 \\
\operatorname{Pt}(131312) \equiv \operatorname{Pt}(\mathrm{s})-[25(111) \times(110)], n-1=25 \\
\operatorname{Pt}(332) \equiv \operatorname{Pt}(\mathrm{s})-[5(111) \times(110)], n-1=5
\end{gathered}
$$

The working electrodes were annealed in a butane/air flame, followed by cooling in a free of oxygen reducing atmosphere of either $\mathrm{Ar} / \mathrm{H}_{2}$ (according to the Clavilier procedure ${ }^{39}$ ) or CO (N47, Alpha Gaz). It has been shown that the thermal treatment in the reducing atmosphere leads to the surface structures that correspond to the nominal values \{herrero, orts\}. Moreover, the voltammetric profile of the electrodes in sulfuric acid, which are very sensitive to the surface structure allows confirming the presence of the nominal surface \{clavilier, rodes\}. The counter electrode was a Pt wire (which was repeatedly annealed in a butane/air flame and washed with ultrapure water before use), while a reversible hydrogen electrode (RHE) was used as the reference electrode. All the potentials were referenced to the RHE scale unless otherwise stated, and were converted to the standard hydrogen electrode (SHE) scale when needed.

CO stripping experiments were performed using the cyclic voltammetry technique. In this case, the preparation of the CO-covered electrode followed two procedures: (1) adsorption of $\mathrm{CO}$ at $0.100 \mathrm{~V}$ in the electrochemical cell, and elimination of the non-adsorbed $\mathrm{CO}$ from the solution; (2) formation of the $\mathrm{CO}_{\text {ads }}$ layer while the flame-annealed Pt electrode was cooled in a $\mathrm{CO}$ atmosphere, and immersion of the $\mathrm{CO}$-covered electrode in the solution, at a constant potential of $0.100 \mathrm{~V}$. These procedures will be better understood from the descriptions for each specific experiment. 
Solutions of $0.1 \mathrm{M} \mathrm{HClO}_{4}$ (Aldrich, 70\%) and $0.1 \mathrm{M} \mathrm{H}_{2} \mathrm{SO}_{4}$ (Suprapur, Merck) were prepared in ultrapure water $(18.2 \mathrm{M} \Omega \mathrm{cm})$. The solutions were degassed using Ar (N50, Alpha Gaz). The potential of the electrode was controlled using a waveform generator (Model 175, EG\&G PARC) together with a potentiostat (Model 551, Amel) and a digital recorder (Model ED 401, eDAC).

\subsection{Temperature Control, Potential Corrections, and Conversion of Potential Scales}

The experiments were performed at temperatures ranging from 283 to $318 \mathrm{~K}$, in intervals of $10 \mathrm{~K}$. The electrochemical cell was immersed in a glass vessel, through which water was circulated from a reservoir, under thermostatic control. When the temperature was changed, Ar gas was bubbled through the solution to ensure fast equilibration of the temperature throughout the medium. The level of the solution in the cell was kept below the level of the temperature-controlled water in the vessel, so that the entire solution remained at a uniform temperature.

The electrochemical cell used had one drawback, in that the reference electrode was outside the cell. Consequently, in experiments with temperature variation, there was an electrolyte temperature difference, with the reference electrode being maintained at the ambient temperature of the laboratory $\left(\sim 25^{\circ} \mathrm{C}\right)$, whereas the working electrode was kept at the temperature of the thermal bath. A non-isothermal electrolyte causes thermal diffusion phenomena in the form of parasitic potential drops that do not allow direct conversion of the measured potential (RHE scale) to the SHE (thermodynamic) scale. The parasitic potential depends on the temperature, solution composition, and nature of the electrolyte (ions). The difference between the corrected and measured potentials, $\Delta E_{\mathrm{TD}}$, is the potential correction due to thermal diffusion. For a $0.1 \mathrm{M} \mathrm{HClO}_{4}$ solution, the term $\Delta E_{\mathrm{TD}} / \Delta T$ was quantitatively obtained as follows ${ }^{40}$ :

$$
\frac{\Delta E_{\mathrm{TD}}}{\Delta T} \simeq-0.381 \mathrm{mV} \mathrm{K}^{-1}
$$

where $\Delta T=T-298 \mathrm{~K}$. The corrected potentials (RHE scale) at the temperature $T$ of the experiments ( $E_{\mathrm{RHE}}, T$ (corrected) $)$ were then calculated as follows:

$$
E_{\mathrm{RHE}, T \text { (corrected) }}=E_{\text {measured }}+E_{\text {correction }}
$$

where the $E_{\text {correction }}$ term was obtained from Equation 1 . Despite slightly decreased precision of the potential determination, an important advantage of using an external reference electrode is that the electroactive elements are maintained under less aggressive conditions. 
This particular choice provides greater stability for the reference electrode, despite a loss in the accuracy, and for this reason, this arrangement was selected. After the above corrections of the potentials, the corrected potentials (RHE scale) at the electrochemical cell temperature were converted to potentials on the standard hydrogen electrode (SHE) scale, at $298 \mathrm{~K}$, as follows ${ }^{41}$ :

$$
\begin{aligned}
& E_{\mathrm{SHE}, T}=E_{\mathrm{RHE}, T}-0.021 \mathrm{~V} \\
& E_{\mathrm{SHE}, 298 \mathrm{~K}}=E_{\mathrm{SHE}, T}+(T-298 \mathrm{~K}) \frac{\partial E}{\partial T}
\end{aligned}
$$

where the coefficient $\partial E / \partial T=8.4 \times 10^{-4} \mathrm{~V} \mathrm{~K}^{-1}$.

\subsection{Activation Energy}

The activation energies for the CO electro-oxidation were calculated using the model described as ${ }^{41}$ :

$$
E_{\mathrm{p}}-E^{0}=\frac{R T}{F} \ln \frac{J_{\mathrm{p}} A_{-1} a_{\mathrm{H}^{+}}}{Q_{\mathrm{p}} A_{1} A_{2} \theta_{\mathrm{CO}, \mathrm{p}} \theta_{\mathrm{H}_{2} O, \mathrm{p}}}+E_{\mathrm{act}}
$$

where $E_{\mathrm{p}}, J_{\mathrm{p}}$, and $Q_{\mathrm{p}}$, are, respectively, the peak potential, the peak current density, and the uncorrected charge of the voltammetric feature due to the $\mathrm{CO}$ electro-oxidation; $E^{0}$ is the standard potential for the electro-oxidation of adsorbed CO (assumed to be $\sim 0.00 \mathrm{VshE}$ ); $A_{i}$ are the pre-exponential factors; $a_{\mathrm{H}^{+}}$is the activity of the protons; $\theta$ co, p and $\theta_{\mathrm{H}_{2} \mathrm{O}, \mathrm{p}}$ are the coverage of $\mathrm{CO}$ and $\mathrm{H}_{2} \mathrm{O}$, respectively, at the peak potential; $F, T$, and $R$ are the Faraday constant, temperature (in kelvins), and the gas constant, respectively. The activation energies $\left(E_{\text {act }}\right.$, in $\left.\mathrm{kJ} \mathrm{mol}^{-1}\right)$, referred to $T=0 \mathrm{~K}$, were determined from the intercepts of the straight lines obtained for the relation $\left(E_{\mathrm{p}}-E^{0}\right)$ versus $T$.

\section{Results}

\subsection{Voltammetric Characterizations of the Electrodes}

Figure 1 shows the voltammetric profiles of the non-defected $\operatorname{Pt}(111), \operatorname{Pt}(2020$ 19), $\mathrm{Pt}\left(1313\right.$ 12), and $\mathrm{Pt}(332)$ electrodes in a $0.1 \mathrm{M} \mathrm{HClO}_{4}$ solution. The figure includes hardsphere models for each crystal surface. For recording these cyclic voltammograms, the $\mathrm{Pt}$ crystal was annealed in a butane/air flame, followed by cooling in a stream of $\mathrm{H}_{2} / \mathrm{Ar}$ (about 1:10 ratio) in a vessel partially filled with ultrapure water. It is standard practice to acquire voltammetric profiles of the electrode only in the electrolyte before recording any other 
desired experiment to assure that the surface is well-ordered, and the solution is clean. These voltammetric profiles were also obtained for the $\mathrm{CO}$ treated electrodes after the stripping of the $\mathrm{CO}_{\text {ads }}$ layer. The cyclic voltammogram of the non-defected $\operatorname{Pt}(111)$ electrode after stripping off the $\mathrm{CO}_{\mathrm{ads}}$ layer formed during the cooling of the electrode in a $\mathrm{CO}$ atmosphere is presented later. Regardless of the orientation of the surface, for potentials below about 0.33 $\mathrm{V}$ (Figure 1), the interfacial electrochemical processes were dominated by the reversible discharge of the proton to form adsorbed hydrogen on the Pt sites, so (disregarding the interfacial water and probably the interfacial anions) the reaction was simply $\mathrm{H}^{+}+\mathrm{e}^{-}+{ }^{*}$ active sites $\rightleftarrows \mathrm{H}_{\text {ads, }}$, the hydrogen adsorption/desorption. This proposal is based on the fact that for $\operatorname{Pt}(111)$-type polarized electrodes, for example, in a perchloric acid solution, the potential of zero total charge is located below $0.33 \mathrm{~V}_{\mathrm{RHE}}{ }^{42}$. Regarding the hydrogen adsorption/desorption, this reaction is fast, surface-limited, and sensitive to the surface structure associated with the Pt sites. The presence of defects on the Pt surface causes a noticeable change in the voltammetric profile, in particular in the hydrogen region. Hence, for $\operatorname{Pt}(111)$ terraced surfaces consisting of (110) steps, the hydrogen adsorption/desorption results in a pair of prominent and symmetric peaks at $\sim 0.13 \mathrm{~V}_{\mathrm{RHE}} 1^{43}$, indicative of a reversible process involving the top of the steps sites. All the features below the peaks at $\sim 0.13 \mathrm{~V}$ are due to the discharges of the proton to form hydrogen adsorbed onto (111) terraces sites, including those sites related to the bottom side of the steps, as illustrated for the $\mathrm{Pt}(332)$ surface in Figure 1. In this figure, the intensities of the pair of peaks at $\sim 0.13 \mathrm{~V}$ increase with increasing density of the crystalline (110) steps $\left(\rho_{(h k))}\right)$, defined as the number of steps per unit length in the plane of the terrace $\left(\rho_{(h k)}\right)$ in $\left.\mathrm{cm}^{-1}\right)$, which follows the order: $\rho_{(332)}>\rho_{(131312)}>\rho_{(202019)}>>\rho_{(111) \text { non-defected, as expected }}$ for a contribution related to the presence of (110) steps. At more positive potentials, a pair of peaks appears at $\sim 0.8 \mathrm{~V}$, probably due to a reversible process involving the (perchlorate) anions and interfacial water molecules, requiring the long-range order of (111) terraces ${ }^{44}$. None of the voltammograms show any signs of (100) defects, which would give rise to a pair of peaks at ca. $0.27 \mathrm{~V}$ for this $\mathrm{pH}$, indicating that the Pt surfaces are well-ordered. In fact, the $\mathrm{H}^{+}+\mathrm{e}^{-}+{ }^{*} \mathrm{H}_{2} \mathrm{O} \rightleftarrows \mathrm{H}_{\text {ads }}+\mathrm{H}_{2} \mathrm{O}$ reactions are so sensitive to the Pt surface structure that surface defects with coverage on the order of $\sim 1 / 150$ can be detected by voltammetry (especially in sulfuric acid solutions). Therefore, it could be inferred that the $\operatorname{Pt}(111)$ used in this study was a non-defected $\operatorname{Pt}(111)$ surface, within the limits of the detection. Further insights about the 
origins of the interfacial processes involving Pt single crystal in aqueous solution can be found in a previous work ${ }^{45}$.

\subsection{Stripping of COads Layers on Different Pt Surface Orientations}

Figure 2 shows the voltammograms for the electro-oxidation of $\mathrm{CO}_{\text {ads }}$ layers formed under two different conditions. In the first case, the $\mathrm{CO}_{\text {ads }}$ layer was formed at a constant potential of $0.100 \mathrm{~V}$ for Pt electrodes which were cooled in an $\mathrm{H}_{2} / \mathrm{Ar}$ (reducing) atmosphere after flame annealing. For the preparation of these $\mathrm{CO}_{\text {ads }}$ layers at $0.100 \mathrm{~V}$, the oriented part of the crystal was immersed in the solution and CO gas was bubbled through the solution for 5 minutes. Next, the $\mathrm{CO}$ flow was interrupted, followed by bubbling of Ar gas through the solution for 20 minutes, for the complete elimination of the non-adsorbed CO. It was extremely important to ensure that all the non-adsorbed $\mathrm{CO}$ had been eliminated from the solution. This can be checked by the absence of a CO electro-oxidation peak in the next positive scan after the CO stripping, in particular, at a slower scan rate, for example, at $10 \mathrm{mV}$ $\mathrm{s}^{-1}$. The CO stripping results, recorded at $50 \mathrm{mV} \mathrm{s}^{-1}$, are shown in Figure 2 (blue line) for four electrode surfaces. For the second procedure, the $\mathrm{CO}_{\text {ads }}$ layer was formed during cooling of the flame annealed Pt crystal in a CO (reducing) atmosphere. In this case, the electrode (while still red) was quickly transferred to a vessel through which a stream of $\mathrm{CO}$ gas had been injected, so the crystal reached room temperature with its surface covered with a COads layer. The CO stripping results are as shown by the orange line in Figure 2. It is important to highlight that the real surface structure of the as-prepared electrode surface is strongly dependent on the chemical nature of the atmosphere in which the crystal was cooled, whether reducing, neutral or oxidizing. For example, the presence of oxygen in the atmosphere in which the Pt crystal was cooled resulted in roughening of the surface, as observed by STM (scanning tunneling microscopy), while a well-ordered $\operatorname{Pt}(111)$ surface was obtained by cooling the flame annealed crystal in reducing and inert atmospheres ${ }^{46}, 47$. Since the voltammograms are very sensitive to the surface structure, these differences in the surface structure result in changes in the voltammetric profiles, and, consequently, changes in the catalytic activity as well.

As shown in Figure 2 (blue line), the stripping of the $\mathrm{CO}_{\text {ads }}$ layer formed on the nondefected $\mathrm{Pt}(111)$ electrode at $0.100 \mathrm{~V}$ presented a single peak, with the $\mathrm{CO}_{\text {ads }}$ layer electrooxidation starting at $\sim 0.7 \mathrm{~V}$ and reaching a maximum at $\sim 0.82 \mathrm{~V}$. In fact, all the CO stripping 
voltammograms for $\mathrm{CO}_{\text {ads }}$ layered at $0.100 \mathrm{~V}$ on the different stepped surfaces showed only a single $\mathrm{CO}$ oxidation peak (insets in Figure 2), and no signals were observed corresponding to the $\mathrm{CO}$ electro-oxidation reaction at potentials of around $\sim 0.6 \mathrm{~V}$. It is important to note that this was only the case where CO oxidation does not occur at low potentials because all the non-adsorbed $\mathrm{CO}$ was deliberately eliminated from the solution. Evidence supporting this statement will be provided later. In Figure 2, as expected, for CO dosed at $0.100 \mathrm{~V}$, the peak potential of CO electro-oxidation moved to less positive potentials when passing from the non-defected $\operatorname{Pt}(111)$ to the $\operatorname{Pt}(332)$ surface, showing that, under those specific experimental conditions described above, surface defects favored the reaction. For the non-defected $\operatorname{Pt}(111)$ surface, the measured CO coverage for CO dosing at $0.100 \mathrm{~V}$, after appropriate correction ${ }^{48}$, was $\theta_{\mathrm{co}} \simeq 0.68$ (with free $\mathrm{CO}$ in the solution phase), which was in agreement with the formation of a $(\sqrt{19} \times \sqrt{19}) R 23.4^{\circ}-13 \mathrm{CO}$ structure ${ }^{26}$.

In the case of the layered $\mathrm{CO}_{\text {ads }}$ obtained during cooling of the non-defected $\operatorname{Pt}(111)$ crystal in a $\mathrm{CO}$ atmosphere (Figure 2, orange line), the CO stripping profile presented two CO electro-oxidation peaks. For example, in the case of the non-defected $\mathrm{Pt}(111)$, the CO electrooxidation starting at $\sim 0.55 \mathrm{~V}$; the main CO electro-oxidation peak appeared at $\sim 0.74 \mathrm{~V}$ (whose average charge density was $\sim 235 \mu \mathrm{C} \mathrm{cm}^{-2}$, after the appropriate corrections ${ }^{48}$ ) and another one appeared at $\sim 0.65 \mathrm{~V}$, which is here denoted unusual CO pre-oxidation, whose average charge density was $\sim 75 \mu \mathrm{C} \mathrm{cm}^{-2}$. The total CO coverage was $\theta \mathrm{co}=0.64 \pm 0.02$ (obtained at a CO stripping temperature of $\sim 300 \mathrm{~K})$. Based on the data above, unusual CO pre-oxidation corresponds to about $24 \%$ [ $\left.\equiv\left(75 \mu \mathrm{C} \mathrm{cm}^{-2} / 310 \mu \mathrm{C} \mathrm{cm}^{-2}\right) \times 100\right]$ of the total charge that crosses the electrode/electrolyte interface during the electro-oxidation of this $\mathrm{CO}_{\text {ads }}$ layer.

The experimental results in Figure 2 presented the following general features: (a) For $\mathrm{CO}_{\text {ads }}$ layered at a constant potential of $0.100 \mathrm{~V}$, the $\mathrm{CO}$ pre-oxidation does not appear, even with the stepped Pt surfaces (it should be noted that the non-adsorbed CO had been completely eliminated from the solution); (b) For both $\mathrm{CO}_{\text {ads }}$ layer preparation procedures, the main $\mathrm{CO}$ electro-oxidation peaks move to less positive potentials as the surface passes from non-defected $\operatorname{Pt}(111)$ to $\operatorname{Pt}(332)$, which was the same direction as the increase in the surface "step density" $\left.\left(\rho_{(h k))}\right): \rho_{(111) \text { non-defected }}<<\rho_{(20} 2019\right)<\rho_{(131312)}<\rho_{(332)}$; (c) For electrodes cooled in a $\mathrm{CO}$ atmosphere, the magnitude of the unusual $\mathrm{CO}$ pre-oxidation decreases as the surface passes from non-defected $\mathrm{Pt}(111)$ to $\mathrm{Pt}(332)$. The unusual CO pre-oxidation did not occur for $\mathrm{Pt}(332)$. Features (b) and (c) indicated that steps on the surface were associated with improved 
catalysis of $\mathrm{CO}$ electro-oxidation in the main electro-oxidation peak, while they suppressed the appearance of the unusual $\mathrm{CO}$ pre-oxidation. Finally, for the layered $\mathrm{CO}_{\text {ads }}$ obtained while the $\mathrm{Pt}(111)$ electrodes were cooled in a $\mathrm{CO}$ atmosphere, the effects of the steps/defects on the surface in suppressing or promoting the activation of reaction pathways in the CO electrooxidation do not extend to the $\mathrm{CO}_{\text {ads }}$ layer as a whole, that is, only the part corresponding to the $\mathrm{CO}$ pre-oxidation or electro-oxidation of $\mathrm{CO}$ at lower overpotentials is suppressed on the defected Pt surfaces (Figure 2).

Experiments similar to those performed using Pt single crystals (CO dosed at $0.100 \mathrm{~V}$ and elimination of the non-adsorbed CO for $20 \mathrm{~min}$ ) were also performed using a bead-type poly-oriented Pt electrode. The results are shown in Figure 3A, where the orange line refers to the electro-oxidative stripping of a $\mathrm{CO}_{\text {ads }}$ layer formed while the flame annealed polyoriented Pt electrode was cooled in a CO atmosphere, while the black line corresponds to the stripping of a $\mathrm{CO}_{\text {ads }}$ layer formed at a constant potential of $0.100 \mathrm{~V}$. It can be seen from Figure $3 \mathrm{~A}$ that there was no unusual $\mathrm{CO}$ pre-oxidation in the stripping of the $\mathrm{CO}_{\text {ads }}$ layer formed during cooling of the electrode in a $\mathrm{CO}$ atmosphere. Furthermore, there was no ordinary CO pre-oxidation for the CO layer formed at $0.100 \mathrm{~V}$, because the non-adsorbed CO was completely eliminated from the solution. Figure 3B shows the corresponding cyclic voltammograms for the bead-type poly-oriented Pt electrode in $0.1 \mathrm{M} \mathrm{HClO}_{4}$ solution. The pair of small peaks appearing at $\sim 0.80 \mathrm{~V}$ could have the same relationships with the feature appearing at $\sim 0.80 \mathrm{~V}$ in the voltammograms for the $\mathrm{Pt}(111)$ electrode in perchloric acid solutions.

As stated above, to provide evidence that, at least, traces of $\mathrm{CO}$ in the solution phase are required for the appearance of the $\mathrm{CO}$ pre-oxidation in voltammograms for $\mathrm{CO}$ stripping employing stepped Pt surfaces, experiments were performed using the $\mathrm{Pt}(332)$ electrode after dosing with $\mathrm{CO}$ at $0.100 \mathrm{~V}$ for 5 minutes, with the application of different $\mathrm{CO}$ elimination times (30, 12, 8, and 5 minutes). The results are shown in Figure 5. On one hand, for long purging times (on the order of 30 minutes), complete elimination of $\mathrm{CO}$ from the solution led to the absence of the $\mathrm{CO}$ pre-oxidation. On the other hand, for shorter purging times, the $\mathrm{CO}$ pre-oxidation appeared around $0.6 \mathrm{~V}$, and its magnitude increased as the time (purging time) was reduced. Similar results were reported for other stepped Pt surfaces in acidic medium ${ }^{17}$. This experiment was important for a broader assessment of the origins of the CO preoxidation, which is the purpose of the present work. 
Most of the electrochemical experiments reported here were performed using perchloric acid solutions. However, experiments were also performed using a sulfuric acid solution $\left(0.1 \mathrm{M} \mathrm{H}_{2} \mathrm{SO}_{4}\right)$. It is well documented that perchlorate anions slightly adsorb on $\mathrm{Pt}(111)$ plane ${ }^{49}$, whereas the sulfate anion $\left(\mathrm{SO}_{4}^{2-}\right)$ specifically adsorbs on the $\mathrm{Pt}(111)$ plane ${ }^{50}$. The adsorption strength of the perchlorate anion is weaker than that of the sulfate anion. Therefore, the evaluation of the influence of the adsorbing anion on the unusual CO preoxidation was made on a non-defected $\mathrm{Pt}(111)$ crystal surface. For this, the $\mathrm{CO}_{\text {ads }}$ layer was obtained while the flame annealed $\mathrm{Pt}(111)$ electrode was cooled in a $\mathrm{CO}$ atmosphere. The stripping of the $\mathrm{CO}_{\text {ads }}$ layer is shown in Figure 5 (orange line). The stripping of a $\mathrm{CO}_{\text {ads }}$ layer formed at $0.100 \mathrm{~V}$ after the elimination of solution $\mathrm{CO}$ for $20 \mathrm{~min}$ is also shown in Figure 5 (blue line). The unusual CO pre-oxidation is marked by the presence of a peak at $\sim 0.65 \mathrm{~V}$, while no CO pre-oxidation is observed for CO dosed at $0.100 \mathrm{~V}$. Hence, regardless of the nature of the electrolyte, that is, solution of perchloric acid and sulfuric acid, the non-defected $\mathrm{Pt}(111)$ electrode is most active for CO electro-oxidation if the layered $\mathrm{CO}_{\text {ads }}$ was acquired while cooling the flame annealed electrode in a $\mathrm{CO}$ atmosphere.

\subsection{Stripping of the CO Layers at Different Temperatures}

A set of $\mathrm{CO}_{\text {ads }}$ layer stripping experiments was performed at temperatures ranging from 283 to $318 \mathrm{~K}$. In this case, the $\mathrm{CO}_{\text {ads }}$ layer was formed by cooling the flame annealed the nondefected $\mathrm{Pt}(111)$ electrode in a $\mathrm{CO}$ atmosphere, as described in the previous section. The electrode covered with $\mathrm{CO}_{\text {ads }}$ was, then, transferred to the electrochemical cell, which was already at the temperature-programmed to perform the CO stripping. The results are shown in Figure 6. The voltammetric profiles exhibit two CO electro-oxidation peaks, which shift to less positive potentials as the CO stripping temperature increases, as expected. For three experiments repeated at the same temperature, we compared the peak potential and current intensity. In these repetitions, the peak potentials for experiments performed differed by only about $3 \mathrm{mV}$, whereas, as an example, the maximum current density varied from $\sim 840$ to $\sim 890$ $\mu \mathrm{A} \mathrm{cm} \mathrm{cm}^{-2}$ at $303 \mathrm{~K}$. The peak currents for $T<313 \mathrm{~K}$ are almost temperature independent. However, as shown in Figure 6, there was a noticeable diminution in the current densities for the main CO electro-oxidation, and the unusual $\mathrm{CO}$ pre-oxidation peaks for $T \geq 313 \mathrm{~K}$ (a similar trend can be seen in Figure 7 of a previous study ${ }^{41}$ ), whose origin is unknown. In addition, the voltammetric features due to the $\mathrm{CO}$ electro-oxidation (considering the unusual 
CO pre-oxidation and main oxidation peaks) became wider with increasing temperature. The influence of temperature on total $\mathrm{CO}_{\text {ads }}$ coverage follows the same trend as that observed for the peak intensity (Table 1 ), : when $T<313 \mathrm{~K}$ the total CO coverage is nearly constant $\left(\theta_{\mathrm{co}} \simeq\right.$ 0.64 ) and diminishes for $T \geq 313 \mathrm{~K}$, where $\theta_{\mathrm{co}} \simeq 0.60$ for $T=313$ and $\theta_{\mathrm{co}} \simeq 0.55$ for $T=318$ $\mathrm{K}$. Table 1 also includes data on charge densities of CO pre-oxidation and the main CO electrooxidation peaks. For CO stripping at temperatures ranging from 283 to about $303 \mathrm{~K}$, the charge densities of unusual CO pre-oxidation were about $24 \%$ of the charge of a complete layer of $\mathrm{CO}_{\text {ads }}$ (Qco pre-oxidation $+Q_{\text {main CO oxidation }}$ ). However, the charge of unusual CO pre-oxidation decreases as the stripping temperature rises above $303 \mathrm{~K}$ (Table 1). For temperature ranging from 283 to $313 \mathrm{~K}$, the peak potentials for the unusual CO pre-oxidation and main oxidation peaks decreased linearly with the increase of the temperature (see Figure 7), with slopes of $1.62 \pm 0.02$ and $-1.64 \pm 0.02 \mathrm{mV} \mathrm{K}^{-1}$, respectively. In this figure, the error bars correspond to the standard deviation of three different measurements. Considering the temperature range from 283 to $313 \mathrm{~K}$ in Figure 7, the intercept of the plot of $E_{\mathrm{p}}-E^{\mathrm{b}} v s . T$ (Equation 5) enabled the determination of the activation energies $\left(E_{\text {act }}\right)$, which were $\sim 108$ and $\sim 117 \mathrm{~kJ} \mathrm{~mol}^{-1}$ for the unusual CO pre-oxidation and main CO electro-oxidation processes, respectively. For the stripping of a CO layer dosed on a $\mathrm{Pt}(111)$ electrode at $0.1 \mathrm{~V}_{\mathrm{RHE}}$ in a $0.1 \mathrm{M} \mathrm{HClO}_{4}$ solution, Herrero et al. ${ }^{41}$ found an activation energy for CO electro-oxidation of $\sim 111 \mathrm{~kJ} \mathrm{~mol}^{-1}$ (this became $\sim 20 \mathrm{~kJ} \mathrm{~mol}^{-1}$ higher in a sulfuric acid solution ${ }^{41}$ ). It has been shown that the activation energy for $\mathrm{CO}_{\text {ads }}$ stripping strongly depends on the potential at which the $\mathrm{CO}_{\text {ads }}$ layer was formed, varying substantially from 1.28 to $2.17 \mathrm{~V}^{51}$.

\subsection{Step-wise Oxidative Stripping of the $\mathrm{CO}_{\text {ads }}$ Layer}

For these experiments shown in Figure 8, the layer of $\mathrm{CO}_{\text {ads }}$ was also formed during cooling of the flame annealed non-defected $\mathrm{Pt}(111)$ electrode in a $\mathrm{CO}$ atmosphere, as described above. The $\mathrm{CO}_{\text {ads }}$ layer was then voltammetrically oxidized in successive steps. The potential of the $\mathrm{CO}$ covered electrode was swept from $0.100 \mathrm{~V}$ up to a value sufficient to oxidize only a small portion of the $\mathrm{CO}_{\text {ads }}$ species responsible for the unusual $\mathrm{CO}$ pre-oxidation process. For this, different upper potential limits were chosen. For example, for the experiments shown in Figure 8A, in the first potential sequence, the potential was swept from $0.100 \mathrm{~V}$ up to $0.62 \mathrm{~V}$, after which it was stepped back to $0.100 \mathrm{~V}$. In the second potential sequence, the upper potential limit was slightly higher than that of the previous step. The 
reason for the progressive increase of the upper potential limit was that the potential required to restart the electro-oxidation of the remaining $\mathrm{CO}_{\text {ads }}$ layer was progressively higher than that required in the previous partial CO electro-oxidation step (Figure 8A). In the third step, the potential was swept from 0.100 up to $0.900 \mathrm{~V}$, to remove the entire remaining $\mathrm{CO}_{\text {ads }}$ layer. As can be seen in Figure 8A, electro-oxidation of the portion of the $\mathrm{CO}_{\text {ads }}$ species responsible for the unusual CO pre-oxidation did not release active sites for the hydrogen desorption, as revealed by the absence of current signals below $0.4 \mathrm{~V}$. In addition, the main $\mathrm{CO}$ electrooxidation peak potential was at $\sim 0.75 \mathrm{~V}$, which was almost the same as in Figure 2.

In the experiments shown in Figure 8B, in the first potential sequence, the potential was swept from 0.100 to $0.7 \mathrm{~V}$, in order to electro-oxidize all the $\mathrm{CO}_{\text {ads }}$ species responsible for the unusual CO pre-oxidation. The potential was then stepped back to $0.100 \mathrm{~V}$, followed shortly afterward by application of a second potential sweep up to $0.900 \mathrm{~V}$, for removal of the remaining $\mathrm{CO}_{\text {ads }}$ layer. In this case, the main $\mathrm{CO}$ electro-oxidation peak potential was $\sim 0.75$ V (Figure 8B), which was similar to the experimental results shown in Figures 2 and 8A. In the case of Figure 8B, the complete electro-oxidative elimination of the $\mathrm{CO}_{\mathrm{ads}}$ species responsible for the unusual $\mathrm{CO}$ pre-oxidation apparently released a very small fraction of $\mathrm{Pt}$ sites active available for the hydrogen desorption, seen at the very beginning of the second cycle (insert of Figure 8B, black line). However, it is possible that the anodic current that appeared at lower potentials (around $0.1 \mathrm{~V}$ ) in the second cycle (Figure 8B, black line) could have been a contribution from the electro-oxidation of $\mathrm{H}_{2}$ released when the potential shifted from 0.100 to $0.06 \mathrm{~V}$, before going to high potentials. The potential required to restart the electro-oxidation of the remaining $\mathrm{CO}_{\text {ads }}$ layer progressively increased, which indicated that there was no reoccupation of the most active sites as they were released during the previous CO electrooxidations steps.

Another important aspect shown in Figure 8 concerns the blank voltammogram for the non-defected $\mathrm{Pt}(111)$ single crystal recorded after $\mathrm{CO}$ stripping. There was no apparent surface restructuring after $\mathrm{CO}$ stripping, similar to the results reported previously ${ }^{14}$. In a study employing in situ STM imaging of Pt(111) after cooling in a CO + $\mathrm{N}_{2}$ (reducing) atmosphere, it was concluded that there were no changes in surface morphology of the $\operatorname{Pt}(111)$ surface after stripping off the $\mathrm{CO}_{\text {ads }}$ layer ${ }^{46}$. On the other hand, $\mathrm{CO}$ adsorption/oxidation cycles can induce a change in the order of the $\operatorname{Pt}(110)$ surface from $\operatorname{Pt}(110)-(1 \times 2)$ to $\operatorname{Pt}(110)-(1 \times 1)^{52}$. At the best, due to the strong binding of the $\mathrm{CO}$ molecules, the cycles of adsorption/oxidation 
are useful for cleaning (and event protecting) the catalyst surfaces (at least, the surfaces with which the CO molecules strongly bind).

Another experiment was carried out involving the $\mathrm{CO}_{\mathrm{ads}}$ layer formed during the cooling of non-defected $\mathrm{Pt}(111)$ in a $\mathrm{CO}$ atmosphere. In this case, before the $\mathrm{CO}_{\text {ads }}$ layer was voltammetrically stripped, the potential was cycled between 0.06 and $\sim 0.45 \mathrm{~V}$ several times. Then, the voltammetric profile of the CO stripping (Figure 9) was very similar to that of the experiment without previous potential cycling (Figure 2, orange line). The result shown in Figure 9 suggested that the structure of the $\mathrm{CO}_{\text {ads }}$ layer was quite stable and should not undergo irreversible restructuring under cycling using potentials lower than the threshold potential for CO electro-oxidation (not shown).

\section{Discussion}

This paper reports that steps/defects on the Pt surfaces can improve as well as worsen the catalytic activity of $\mathrm{Pt}$ electrodes toward the electro-oxidation of $\mathrm{CO}$ at low overpotentials, depending on the method used to prepare the $\mathrm{CO}_{\text {ads }}$ layer. This indicates that surface defects can provide different functionalities in the electrocatalysis of $\mathrm{CO}$ oxidation on platinum electrodes. It also indicates that the pre-oxidation of $\mathrm{CO}$ has different origins.

\subsection{Origins of the CO Pre-oxidation and the Functionalities of the Surface Defects}

The origin of the CO pre-oxidation and the set of experimental conditions that should be fulfilled to ensure its appearance on $\mathrm{Pt}(111)$-type electrodes in acid media were reported in a previous paper ${ }^{17}$. The present study confirms that these same experimental conditions also apply to poly-oriented $\mathrm{Pt}$ in acid media (Figure 3A). For the surfaces of the $\operatorname{Pt}(\mathrm{s})-[(n-$ $1)(111) \times(110)$ ] series, which are surfaces consisting of (111) terraces periodically broken by (110) monoatomic steps, the set of most active sites involved in the CO pre-oxidation lie at the bottom side of the steps (and close to them). On these stepped surfaces, these most active sites are (111), whose tuning in the catalytic activity is related to the phenomenon of electronic charge separation between the top and bottom of the steps (as explained elsewhere $\left.{ }^{13}\right)$. A similar phenomenon is the Smoluchowski effect ${ }^{53}$, which involves charge redistribution at the steps, with the top part of the step having a positive charge, while negative charge accumulation occurs in the counterpart. Thus, due to the electronic charge separation, steps/defects on the surface can be understood as a dipole on the surface. It was proposed that 
steps on the surfaces do not, by themselves, act directly as the most active sites in the electrocatalysis of the CO electro-oxidation reaction, but instead act by altering the stability of the neighboring sites ${ }^{13}$. This means that the steps/defects on the surfaces are the origin of the "creation" of the most active sites on the (111) terraces. Therefore, the 2D characteristics of such most active sites can explain the origin of the $\mathrm{CO}$ pre-oxidation on surfaces of the $\mathrm{Pt}(\mathrm{s})-[(n-1)(111) \times(110)]$ series, as well as poly-oriented $\mathrm{Pt}$, under certain specific conditions of CO coverage and potential of CO dosage (Figures 2, 3, and 4). Hence, under the conditions specified above, in particular the origin of $\mathrm{CO}_{\text {ads }}$ from direct $\mathrm{CO}$ dosing (or dissociation of alcohols ${ }^{13}$ ), surface defects are necessary ingredients that indirectly favor activation of the pathways for CO electro-oxidation on (111) terraces, at low overpotentials.

The conclusion reached above does not explain the occurrence of the unusual CO preoxidation on the non-defected $\mathrm{Pt}(111)$ surface, mainly due to the lack of defects on the surface, or rather, because the surface defects deteriorate the catalysis, as we can conclude from the data in Figure 2. On one hand, it is noteworthy that the position of the peak potential of the unusual CO pre-oxidation hardly varied with the (111) terrace width or the equivalent density of surface steps (Figure 2). On the other hand, another intriguing aspect is that the peak potentials for the main CO electro-oxidation processes moved significantly toward lower overpotentials, as defects were introduced on the surface, in parallel with suppression of the unusual CO pre-oxidation (Figure 2). This strongly indicated that for the same layer of $\mathrm{CO}_{\text {ads, }}$ the steps/defects on the surface did not equally or in the same way affect both "catalytic" processes involving the entire $\mathrm{CO}_{\text {ads }}$ layer. Hence, the unusual $\mathrm{CO}$ pre-oxidation and main $\mathrm{CO}$ electro-oxidation peaks appeared to be kinetically decoupled. Indeed, the decoupling of the two processes enabled calculation of the activation energies for the unusual CO pre-oxidation and the main CO electro-oxidation as $\sim 108$ and $\sim 117 \mathrm{~kJ} \mathrm{~mol}^{-1}$, respectively, using the effect of the temperature on the peak potentials. Thus, employing stepped Pt surfaces, the data (Figure 2) suggested that the entire population of $\mathrm{CO}_{\mathrm{ads}}$ species forming the $\mathrm{CO}_{\text {ads }}$ layer was not uniformly affected by defects on the surface. Consequently, from the catalysis viewpoint, this strongly suggested that there was no single type of active site that operated in the entire $\mathrm{CO}_{\mathrm{ads}}$ electro-oxidation layer. Hence, from a 2D perspective of the active sites for the CO electrooxidation reaction, even the perfect $\operatorname{Pt}(111)$ surface behaves as a heterogeneous surface. The possible causes for the heterogeneity of active sites for $\mathrm{CO}$ electro-oxidation on a nondefected $\operatorname{Pt}(111)$ surface will be addressed later. Then, concerning the influence of the 
steps/defects in the origin of the unusual CO pre-oxidation, one hypothesis is that the steps on the surface "inhibit" the formation (or existence) of $\mathrm{CO}_{\text {ads }}$ species responsible for the unusual CO pre-oxidation, because long-range order on the (111) plane is required. Hence, for similar Pt surfaces in the presence of a similar electrolyte, it is highly possible that there are many causes of $\mathrm{CO}$ pre-oxidation, including the unusual pre-oxidation that occurs with non-defected $\operatorname{Pt}(111)$ electrode. Curiously, at least for the surfaces of the $\operatorname{Pt}(\mathrm{s})-[(n-$ $1)(111) \times(110)$ ] series, one interesting aspect that unifies both "ordinary" CO pre-oxidation and the unusual CO pre-oxidation is that the most active sites involved in these processes undoubtedly reside on the (111) terrace sites. The difference is that the defects on the surface are beneficial for only one of these CO pre-oxidation processes, as discussed above. Different from what has until now been believed, even a perfect $\operatorname{Pt}(111)$ single crystal would be very active toward the electro-oxidation of CO. Therefore, based on the above, it is reasonable to state that the steps/defects on the surfaces, under certain experimental conditions, play roles that very often result in the catalytic promotion of electro-oxidation of CO on Pt (based on the data shown in Figures 2-4). The term "very often" is used here, because an exception was identified, so there was no general condition whereby steps on the surface always favored catalysis of the electro-oxidation, even on a similar $(\mathrm{Pt})$ surface in a similar electrolyte.

In addition to surface defects, another parameter that decreased the unusual CO preoxidation was the CO stripping temperature (Table 1). Conceptually, the increase in temperature has an impact on the surface $(\mathrm{CO})$ coverage because it increases the desorption rate. When there are $\mathrm{CO}_{\text {ads }}$ species with different desorption energies, it is expected that adsorbed species would preferentially desorb from the sites where they are most weakly bonded ${ }^{54,55}$. On the other hand at high surface coverage, lateral interactions among adsorbed species become important in determining the energy of adsorption ${ }^{56}$. Since the charge density of unusual CO pre-oxidation was most proportionally affected (decreased) with increasing temperature, this indicated that the weakly adsorbed CO species were the species desorbed from the $\operatorname{Pt}(111)$ surfaces. In fact, for $T<313 \mathrm{~K}$, the charge density of the main peak of CO electro-oxidation was almost the same. Therefore, the weakly adsorbed CO species were the ones that were preferentially desorbed, which are the $\mathrm{CO}_{\mathrm{ads}}$ species whose electro-oxidation reaction would give rise to the unusual CO pre-oxidation. Hence, at least on the Pt electrodes, weakly adsorbed CO species were those that electro-oxidized at the lowest overpotentials. However, it should be noted that it was considered that the catalysis (of the CO pre-oxidation) 
was related to certain characteristics of the possible structure of the $\mathrm{CO}_{\text {ads }}$ layer formed during the cooling of the electrode in a $\mathrm{CO}$ atmosphere. Hence, for a $\mathrm{CO}$ electro-oxidation reaction that exhibits the unusual pre-oxidation and main $\mathrm{CO}$ electro-oxidation peaks, the heterogeneity of active sites on non-defected $\mathrm{Pt}(111)$ may actually be a reflection of possible lateral interactions among $\mathrm{CO}_{\text {ads }}$ species and, consequently, a reflection of the structure of the $\mathrm{CO}_{\text {ads }}$ species in the compact layer. This increases the complexity of the nature of the active sites involved in the electrocatalysis of CO oxidation, in particular on (111) terrace sites. It should be noted that it is likely that the identity of the $\mathrm{CO}_{\text {ads }}$ structure was preserved, to a certain degree, even with transfer of the (CO-covered) electrode to the electrochemical cell.

The results described above were compatible with the formation of different ordered structures of $\mathrm{CO}_{\text {ads }}$ on the non-defected $\mathrm{Pt}(111)$ electrode. The transition between them could give rise to the existence of $\mathrm{CO}$ pre-oxidation. Thus, when the $\mathrm{CO}$ was adsorbed from solution, the non-defected $\operatorname{Pt}(111)$ electrode at the constant potential of $0.1 \mathrm{~V}_{\text {RHE }}$ gave CO coverage values that were in agreement with the formation of a nearly perfect $(\sqrt{19} \times \sqrt{19}) R 23.4^{\circ}-13 \mathrm{CO}$ structure $\left(\theta_{\mathrm{CO}} \simeq 0.68\right)$. On the other hand, for $\mathrm{CO}_{\text {ads }}$ layered during cooling of the electrode in a $\mathrm{CO}$ atmosphere, despite full blocking of the platinum sites, the lower coverage values indicated that this structure was not achieved, or, if it was formed, it had a large number of defects. On these defects on the $\mathrm{CO}_{\text {ads }}$ layer (which do not correspond to defects on the $\mathrm{Pt}(111)$ surface), the CO electro-oxidation starts at lower potential. Then, the appearance of the $\mathrm{CO}$ pre-oxidation may be related to the transition of a $\mathrm{CO}_{\text {ads }}$ structure to a second $\mathrm{CO}_{\text {ads }}$ structure with lower coverage. As a matter of fact, $\mathrm{CO}_{\text {ads }}$ structures on $\operatorname{Pt}(111)$ electrode with low coverage have been already observed ${ }^{26}$. Thus, on the $\operatorname{Pt}(111)$ electrode, the $\mathrm{CO}$ pre-oxidation can be then associated with the phase transition between two stable $\mathrm{CO}_{\text {ads }}$ layers, which is initiated on the defects of the $\mathrm{CO}_{\text {ads }}$ layer. Thus, when the layer is formed by dosing $\mathrm{CO}$ in solution, the $\mathrm{CO}_{\text {ads }}$ layer is almost perfect, and the phase transition is then hindered, so that when the potential reaches the value required for it, the whole $\mathrm{CO}_{\text {ads }}$ layer is oxidized in a single peak. However, for the $\mathrm{CO}_{\text {ads }}$ layer formed when $\mathrm{CO}$ is dosed in the cooling atmosphere, the transition likely starts on the defects of the $\mathrm{CO}_{\text {ads }}$ layer, giving rise to the $\mathrm{CO}$ pre-oxidation. The diminution of the charge involved with the unusual $\mathrm{CO}$ pre-oxidation with the increasing step density clearly indicates that the second layer, with the lower coverage, is only stable on long-range order (111) domains. 
Studies with surfaces of the $\operatorname{Pt}(\mathrm{s})-[(n-1)(100) \times(110)]$ series could lead to an even more comprehensive understanding of the origins of the $\mathrm{CO}$ pre-oxidation. This, combined with what is already known for the $\operatorname{Pt}(\mathrm{s})-[(n-1)(111) \times(110)]$ surfaces, would provide further elucidation of the processes occurring on polycrystalline surfaces.

\subsection{Correlations between Structure and Activity of the Pt(111)-type Surfaces}

Employing stepped surfaces of the $\operatorname{Pt}(\mathrm{s})-[(n-1)(111) \times(110)]$ series, it was shown that the catalytic activity for the CO electro-oxidation reaction increased as the (111) planes became rich in defects ${ }^{18,21}$. On one hand, as shown by the data in Figure 2 (blue line), for a layer of $\mathrm{CO}_{\text {ads }}$ formed at $0.100 \mathrm{~V}$, the catalytic activities of the Pt surfaces were in the order ( similar to previous results $\left.{ }^{9}\right): \operatorname{Pt}(332)>\operatorname{Pt}\left(1313\right.$ 12) $>\operatorname{Pt}\left(2020\right.$ 19) $>\operatorname{Pt}(111)_{\text {non-defected. Hence, }}$ an evident correlation was established between surface structure and catalytic activity for the $\mathrm{CO}$ electro-oxidation reaction. It was not previously known that the structure-activity correlations should take into consideration the method used to prepare the $\mathrm{CO}_{\text {ads }}$ layer, which probably influences the way that the $\mathrm{CO}_{\text {ads }}$ species become compacted in the layer. Then, on the other hand, for a $\mathrm{CO}_{\text {ads }}$ layer formed during cooling of the electrode in a $\mathrm{CO}$ atmosphere, as shown by the data in Figure 2 (orange line), the influence of the surface structure on the catalytic activity at low potentials followed the order: $\operatorname{Pt}(111)_{\text {non-defected }}>\operatorname{Pt}(2020$ 19) $>\operatorname{Pt}(13$ 13 12) > Pt(332). For the main CO electro-oxidation peak, the order was: $\operatorname{Pt}(332)>\operatorname{Pt}(1313$

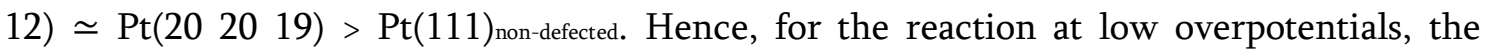
structure-activity relationships showed the exact opposite trends in the two cases. This was an interesting finding of the present work. Therefore, at least for the $\mathrm{CO}$ electro-oxidation reaction, the data suggested that instead of referring to structure-activity relationships (cause and effect relationships), it may be more appropriate to refer to the correlation between surface structure and catalytic activity (catalytic properties), because the surface structure alone is not a determinant cause of the activity of the catalysts.

\section{Main Conclusions}

An investigation was made of the role of surface defects in the electro-oxidation reactions of $\mathrm{CO}_{a d s}$ layers on $\mathrm{Pt}(111)$-type surfaces in $0.1 \mathrm{M} \mathrm{HClO}_{4}$. At low overpotentials, defects on the Pt surfaces had a strong influence, favoring or inhibiting the pathways for CO electro-oxidation on these catalysts, depending on the way that the $\mathrm{CO}_{\text {ads }}$ layer was prepared 
or the (electro-chemical) environment of $\mathrm{CO}_{\text {ads }}$ layer formation. For a $\mathrm{CO}_{\text {ads }}$ layer formed at a constant potential, the defects on the surfaces enhanced the catalysis of the CO electrooxidation reaction, considering both the $\mathrm{CO}$ pre-oxidation (at low overpotentials) and the main CO electro-oxidation peak (at high overpotentials), as expected. In this case, (111) terraces behave as the most active sites, and the catalytic improvement by steps is likely because steps can modify the neighboring (111) terraces below the steps. On the other hand, for a $\mathrm{CO}_{\text {ads }}$ layer formed during cooling of the flame annealed $\mathrm{Pt}(111)$ electrode in a $\mathrm{CO}$ atmosphere, defects on the surfaces impaired the pathways for $\mathrm{CO}$ electro-oxidation at low overpotentials (reflected by unusual CO pre-oxidation) and favored the electro-oxidation of $\mathrm{CO}$ at high overpotentials (reflected by the main $\mathrm{CO}$ electro-oxidation peak). In this case, the most active sites correspond to a situation that requires long-range order on the (111) plane, which corresponds to the "infinite" (111) terrace in an ideal situation, which is not present in the stepped surfaces. The results showed that for $\mathrm{CO}$ electro-oxidation, under particular experimental conditions, defects on the surfaces could play roles that very often result in the promotion of the catalytic activity. Therefore, at least on extended platinum surfaces, there is no general condition that the defects on the surface always favor the electrocatalysis of $\mathrm{CO}$ oxidation. However, it can be said that the electro-oxidation is triggered by the presence of defects in the surface or in the layer, with the specific characteristics of the COads layer determining which types of defects are active for a given $\mathrm{CO}_{\text {ads }}$ layer structure. The data obtained in this work provided evidence that, at least for the CO electro-oxidation reaction at low overpotentials, the structure of the catalyst surface alone is not a factor that determines the catalytic activity.

\section{Acknowledgments}

M.J.S.F. is grateful to CAPES (Brazil). A.A.T. acknowledges CAPES (Processo 88887.124173/2014-00-2013), CNPq (Processo 554610/2010-8), and FAPEMA (APPUNIVERSAL 01150-070). J.M.F and E.H. thank the Ministerio de Ciencia e Innovación (Spain) for the financial support through project PID2019-105653GB-I00. 


\section{References}

1. Somorjai, G. A.; Li, Y., Introduction to Surface Chemistry and Catalysis. John Wiley \& Sons: 2010.

2. Vattuone, L.; Savio, L.; Rocca, M., Bridging the Structure Gap: Chemistry of Nanostructured Surfaces at Well-defined Defects. Surf. Sci. Rep. 2008, 63(3), 101-168.

3. Somorjai, G. A.; Park, J. Y., Molecular Surface Chemistry by Metal Single Crystals and Nanoparticles from Vacuum to High Pressure. Chem. Soc. Rev. 2008, 37(10), 21552162.

4. Koper, M. T. M., Structure Sensitivity and Nanoscale Effects in Electrocatalysis. Nanoscale 2011, 3(5), 2054-2073.

5. Trindell, J. A.; Duan, Z.; Henkelman, G.; Crooks, R. M., Well-Defined Nanoparticle Electrocatalysts for the Refinement of Theory. Chem. Rev. 2020, 120 (2), 814-850.

6. López-Cudero, A.; Cuesta, A.; Gutiérrez, C., Potential Dependence of the Saturation CO Coverage of Pt Electrodes: The Origin of the Pre-Peak in CO-Stripping

Voltammograms. Part 1: Pt(111). J. Electroanal. Chem. 2005, 579(1), 1-12.

7. Kita, H.; Shimazu, K.; Kunimatsu, K., Electrochemical Oxidation of CO on Pt In Acidic and Alkaline Solutions: Part I. Voltammetric Study on the Adsorbed Species and Effects of Aging and Sn(IV) Pretreatment. J. Electroanal. Electrochem. 1988, 241 (1), 163179.

8. Lebedeva, N. P.; Koper, M. T. M.; Herrero, E.; Feliu, J. M.; Van Santen, R. A., Cooxidation on Stepped $\operatorname{Pt}[\mathrm{n}(111) \times(111)]$ Electrodes. J. Electroanal. Chem. 2000, 487(1), 3744.

9. Lebedeva, N. P.; Koper, M. T. M.; Feliu, J. M.; Van Santen, R. A., Role of Crystalline Defects in Electrocatalysis: Mechanism and Kinetics of CO Adlayer Oxidation on Stepped Platinum Electrodes. J. Phys. Chem. B 2002, 106 (50), 12938-12947.

10. Santos, E.; Leiva, E. P. M.; Vielstich, W., CO Adsorbate on Pt(111) Single Crystal Surfaces. Electrochim. Acta 1991, 36 (3), 555-561.

11. Dubau, L.; Nelayah, J.; Moldovan, S.; Ersen, O.; Bordet, P.; Drnec, J.; Asset, T.; Chattot, R.; Maillard, F., Defects Do Catalysis: CO Monolayer Oxidation and Oxygen Reduction Reaction on Hollow PtNi/C Nanoparticles. ACS Catal. 2016, 6 (7), 4673-4684. 12. Barbosa, A. F. B.; Del Colle, V.; Gómez-Marín, A. M.; Angelucci, C. A.; TremiliosiFilho, G., Effect of the Random Defects Generated on the Surface of $\mathrm{Pt}(111)$ on the Electrooxidation of Ethanol: An Electrochemical Study. ChemPhysChem 2019, 20 (22), 3045-3055. 13. Farias, M. J. S.; Cheuquepán, W.; Tanaka, A. A.; Feliu, J. M., Identity of the Most and Least Active Sites for Activation of the Pathways for $\mathrm{CO}_{2}$ Formation from the Electrooxidation of Methanol and Ethanol on Platinum. ACS Catal. 2020, 10 (1), 543-555.

14. Farias, M. J. S.; Cheuquepán, W.; Tanaka, A. A.; Feliu, J. M., Requirement of Initial Long-Range Substrate Structure in Unusual CO Pre-Oxidation on $\mathrm{Pt}(111)$ Electrodes. Electrochem. Commun. 2018, 97, 60-63.

15. Cuesta, Á.; Gutiérrez, C., CO Adsorption on Platinum Electrodes. In Catalysis in Electrochemistry, John Wiley \& Sons, Inc.: 2011; pp 339-373.

16. Batista, E. A.; Iwasita, T.; Vielstich, W., Mechanism of Stationary Bulk CO Oxidation on $\mathrm{Pt}(111)$ Electrodes. J. Phys. Chem. B 2004, 108 (38), 14216-14222.

17. Farias, M. J. S.; Camara, G. A.; Feliu, J. M., Understanding the CO Preoxidation and the Intrinsic Catalytic Activity of Step Sites in Stepped Pt Surfaces in Acidic Medium. J. Phys. Chem. C 2015, 119 (35), 20272-20282.

18. Ren, X.; Gobrogge, E. A.; Lundgren, C. A., Titrating Pt Surface with CO Molecules. J. Phys. Chem. Lett. 2019, 10 (20), 6306-6315. 
19. Silva, C. D.; Cabello, G.; Christinelli, W. A.; Pereira, E. C.; Cuesta, A., Simultaneous Time-Resolved ATR-SEIRAS and CO-Charge Displacement Experiments: The Dynamics of CO Adsorption on Polycrystalline Pt. J. Electroanal. Chem. 2017, 800, 25-31.

20. Farias, M. J. S.; Tanaka, A. A.; Tremiliosi-Filho, G.; Feliu, J. M., On the Apparent Lack of Preferential Site Occupancy and Electrooxidation of CO Adsorbed at Low Coverage onto Stepped Platinum Surfaces. Electrochem. Commun. 2011, 13 (4), 338-341.

21. Farias, M. J. S.; Herrero, E.; Feliu, J. M., Site Selectivity for CO Adsorption and Stripping on Stepped And Kinked Platinum Surfaces in Alkaline Medium. J. Phys. Chem. C 2013, $117(6), 2903-2913$.

22. Cuesta, A.; Pérez, M. D. C.; Rincón, A.; Gutiérrez, C., Adsorption Isotherm of CO on Pt(111) Electrodes. ChemPhysChem 2006, 7(11), 2346-2351.

23. Jung, C.; Kim, J.; Rhee, C. K., Electrochemical Scanning Tunneling Microscopic Observation of the Preoxidation Process of CO on Pt(111) Electrode Surface. Langmuir 2007, 23 (18), 9495-9500.

24. Wei, J.; Amirbeigiarab, R.; Chen, Y.-X.; Sakong, S.; Gross, A.; Magnussen, O. M., The Dynamic Nature of CO Adlayers on Pt(111) Electrodes. Angew. Chem. Int. Ed. 2020, 59 (15), 6182-6186.

25. Rodes, A.; Gómez, R.; Feliu, J. M.; Weaver, M. J., Sensitivity of Compressed Carbon Monoxide Adlayers on Platinum(111) Electrodes to Long-Range Substrate Structure: Influence of Monoatomic Steps. Langmuir 2000, 16(2), 811-816.

26. Villegas, I.; Weaver, M. J., Carbon Monoxide Adlayer Structures on Platinum (111) Electrodes: A Synergy Between in-situ Scanning Tunneling Microscopy and Infrared Spectroscopy. J. Chem. Phys. 1994, 101 (2), 1648-1660.

27. Cuesta, A., The Oxidation of Adsorbed CO on $\mathrm{Pt}(100)$ Electrodes in the Pre-peak Region. Electrocatal. 2010, 1 (1), 7-18.

28. Rudnev, A. V.; Kuzume, A.; Fu, Y.; Wandlowski, T., CO oxidation on Pt(100): New Insights Based on Combined Voltammetric, Microscopic and Spectroscopic Experiments. Electrochim. Acta 2014, 133, 132-145.

29. Samjeské, G.; Komatsu, K. I.; Osawa, M., Dynamics of CO Oxidation on a Polycrystalline Platinum Electrode: A Time-Resolved Infrared Study. J. Phys. Chem. C 2009, 113 (23), 10222-10228.

30. Yan, Y. G.; Yang, Y. Y.; Peng, B.; Malkhandi, S.; Bund, A.; Stimming, U.; Cai, W. B., Study of CO Oxidation on Polycrystalline Pt Electrodes in Acidic Solution by ATR-SEIRAS. J. Phys. Chem. C2011, 115(33), 16378-16388.

31. Brimaud, S.; Pronier, S.; Coutanceau, C.; Léger, J. M., New Findings on CO Electrooxidation at Platinum Nanoparticle Surfaces. Electrochem. Commun. 2008, 10 (11), 1703-1707.

32. Brimaud, S.; Jusys, Z.; Jürgen Behm, R., Shape-Selected Nanocrystals for in situ Spectro-Electrochemistry Studies on Structurally Well Defined Surfaces under Controlled Electrolyte Transport: A Combined in situ ATR-FTIR/Online DEMS Investigation of CO Electrooxidation on Pt. Beilstein J. Nanotechnol. 2014, 5(1), 735-746.

33. López-Cudero, A.; Cuesta, Á.; Gutiérrez, C., Potential Dependence of the Saturation CO Coverage of Pt Electrodes: The Origin of the Pre-Peak in CO-Stripping Voltammograms. Part 2: Pt(100). J. Electroanal. Chem. 2006, 586 (2), 204-216.

34. García, G.; Koper, M. T. M., Stripping Voltammetry of Carbon Monoxide Oxidation on Stepped Platinum Single-Crystal Electrodes in Alkaline Solution. Phys. Chem. Chem. Phys. 2008, 10 (25), 3802-3811. 
35. Wieckowski, A.; Rubel, M.; Gutiérrez, C., Reactive Sites in Bulk Carbon Monoxide Electro-Oxidation on Oxide-Free Platinum(111). J. Electroanal. Chem. 1995, 382 (1-2), 97101.

36. Stamenkovic, V.; Chou, K. C.; Somorjai, G. A.; Ross, P. N.; Markovic, N. M., Vibrational Properties of $\mathrm{CO}$ at the $\mathrm{Pt}(111)$-Solution Interface: The Anomalous StarkTuning Slope. J. Phys. Chem. B 2005, 109 (2), 678-680.

37. Inukai, J.; Tryk, D. A.; Abe, T.; Wakisaka, M.; Uchida, H.; Watanabe, M., Direct STM Elucidation of the Effects of Atomic-Level Structure on $\mathrm{Pt}(111)$ Electrodes for Dissolved CO Oxidation. J. Am. Chem. Soc. 2013, 135 (4), 1476-1490.

38. Lang, B.; Joyner, R. W.; Somorjai, G. A., Low Energy Electron Diffraction Studies of High Index Crystal Surfaces of Platinum. Surf. Sci. 1972, 30 (2), 440-453.

39. Clavilier, J.; Armand, D.; Sun, S. G.; Petit, M., Electrochemical Adsorption Behaviour of Platinum Stepped Surfaces in Sulphuric Acid Solutions. J. Electroanal. Chem. 1986, 205 (1-2), 267-277.

40. Garcia-Araez, N.; Climent, V.; Feliu, J. M., 1 Temperature Effects on Platinum Single-Crystal/Aqueous Solution Interphases. Combining Gibbs Thermodynamics with Laser-Pulsed Experiments. In Interfacial Phenomena in Electrocatalysis, Vayenas, C. G., Ed. Springer New York: New York, NY, 2011; pp 1-105.

41. Herrero, E.; Álvarez, B.; Feliu, J. M.; Blais, S.; Radovic-Hrapovic, Z.; Jerkiewicz, G., Temperature Dependence of the $\mathrm{CO}_{\text {ads }}$ Oxidation Process on $\mathrm{Pt}(111), \operatorname{Pt}(100)$, and $\mathrm{Pt}(110)$ Electrodes. J. Electroanal. Chem. 2004, 567 (1), 139-149.

42. Gómez, R.; Climent, V.; Feliu, J. M.; Weaver, M. J., Dependence of the Potential of Zero Charge of Stepped Platinum (111) Electrodes on the Oriented Step-Edge Density: Electrochemical Implications and Comparison with Work Function Behavior. J. Phys. Chem. B 2000, 104 (3), 597-605.

43. Clavilier, J.; El Achi, K.; Rodes, A., In Situ Probing of Step and Terrace Sites on $\mathrm{Pt}(\mathrm{S})-[\mathrm{n}(111) \times(111)]$ Electrodes. Chem. Phys. 1990, 141 (1), 1-14.

44. Berná, A.; Climent, V.; Feliu, J. M., New Understanding of the Nature of $\mathrm{OH}$ Adsorption on $\mathrm{Pt}(111)$ Electrodes. Electrochem. Commun. 2007, 9 (12), 2789-2794.

45. Huang, Y.-F.; Kooyman, P. J.; Koper, M. T. M., Intermediate Stages of Electrochemical Oxidation of Single-Crystalline Platinum Revealed by In Situ Raman Spectroscopy. Nat. Commun. 2016, 7, 12440.

46. Kibler, L. A.; Cuesta, A.; Kleinert, M.; Kolb, D. M., In-Situ STM Characterisation Of The Surface Morphology of Platinum Single Crystal Electrodes as a Function of Their Preparation. J. Electroanal. Chem. 2000, 484 (1), 73-82.

47. Herrero, E.; Orts, J. M.; Aldaz, A.; Feliu, J. M., Scanning Tunneling Microscopy and Electrochemical Study of the Surface Structure of $\mathrm{Pt}(10,10,9)$ and $\mathrm{Pt}(11,10,10)$ Electrodes Prepared under Different Cooling Conditions. Surf. Sci. 1999, 440(1-2), 259-270.

48. Gómez, R.; Feliu, J. M.; Aldaz, A.; Weaver, M. J., Validity of Double-Layer ChargeCorrected Voltammetry for Assaying Carbon Monoxide Coverages on Ordered Transition Metals: Comparisons with Adlayer Structures in Electrochemical and Ultrahigh Vacuum Environments. Surf. Sci. 1998, 410(1), 48-61.

49. Attard, G. A.; Brew, A.; Hunter, K.; Sharman, J.; Wright, E., Specific Adsorption of Perchlorate Anions on Pt\{hkl\} Single Crystal Electrodes. Phys. Chem. Chem. Phys. 2014, 16 (27), 13689-13698.

50. Zhang, I. Y.; Zwaschka, G.; Wang, Z.; Wolf, M.; Campen, R. K.; Tong, Y., Resolving the Chemical Identity of $\mathrm{H}_{2} \mathrm{SO}_{4}$ Derived Anions on $\mathrm{Pt}(111)$ Electrodes: They're Sulfate. Phys. Chem. Chem. Phys. 2019, 21 (35), 19147-19152. 
51. Rincón, A.; Pérez, M. C.; Cuesta, A.; Gutiérrez, C., Dependence on the CO Admission Potential of the Activation Energy of the Electrooxidation of Adsorbed CO on Pt. Electrochem. Commun. 2005, 7(10), 1027-1032.

52. Attard, G. A.; Hunter, K.; Wright, E.; Sharman, J.; Martínez-Hincapié, R.; Feliu, J. M., The Voltammetry of Surfaces Vicinal to Pt $\{110\}$ : Structural Complexity Simplified by CO Cooling. J. Electroanal. Chem. 2017, 793, 137-146.

53. Smoluchowski, R., Anisotropy of the Electronic Work Function of Metals. Phys. Rev. 1941, 60(9), 661-674.

54. $\quad$ Creighan, S. C.; Mukerji, R. J.; Bolina, A. S.; Lewis, D. W.; Brown, W. A., The Adsorption of CO on the Stepped Pt $\{211\}$ Surface: A Comparison of Theory and Experiment. Catal. Lett. 2003, 88 (1), 39-45.

55. Tränkenschuh, B.; Fritsche, N.; Fuhrmann, T.; Papp, C.; Zhu, J. F.; Denecke, R.; Steinrück, H. P., A Site-Selective In Situ Study of CO Adsorption and Desorption on Pt(355). J. Chem. Phys. 2006, 124 (7).

56. Ertl, G.; Neumann, M.; Streit, K. M., Chemisorption of CO on the Pt(111) Surface. Surf. Sci. 1977, 64(2), 393-410. 
Table 1. Influence of the temperature on $\mathrm{CO}_{a d s}$ coverage on non-defected $\mathrm{Pt}(111)$ electrodes. The data refer to Figure 6. Qco pre-oxidation is the charge (in $\mu \mathrm{C} \mathrm{cm}^{-2}$ ) of unusual CO pre-oxidation;

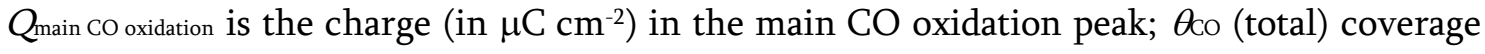
of a complete layer of $\mathrm{CO}_{\text {ads; }} \%$ Qco pre-oxidation is the percentage of the charge density of the unusual CO pre-oxidation. Data refer to three different experiments performed at each temperature.

\begin{tabular}{ccccc}
\hline Temperature (K) & $\begin{array}{c}Q c 0 \text { pre-oxidation } \\
/ \mu \mathrm{Cm}^{-2}\end{array}$ & $\begin{array}{c}Q_{\text {main }} \text { co oxidation } \\
/ \mu \mathrm{C} \mathrm{cm}^{-2}\end{array}$ & $\theta$ co (total) & $\%$ Qco pre-oxidation \\
\hline 283 & $76 \pm 2$ & $234 \pm 1$ & $0.64 \pm 0.00$ & 24.5 \\
293 & $69 \pm 8$ & $237 \pm 3$ & $0.64 \pm 0.02$ & 22.5 \\
303 & $75 \pm 5$ & $235 \pm 5$ & $0.64 \pm 0.02$ & 24.1 \\
313 & $60 \pm 3$ & $229 \pm 1$ & $0.60 \pm 0.00$ & 21.8 \\
318 & $46 \pm 6$ & $220 \pm 7$ & $0.55 \pm 0.01$ & 17.3 \\
\hline
\end{tabular}




\section{Figures}
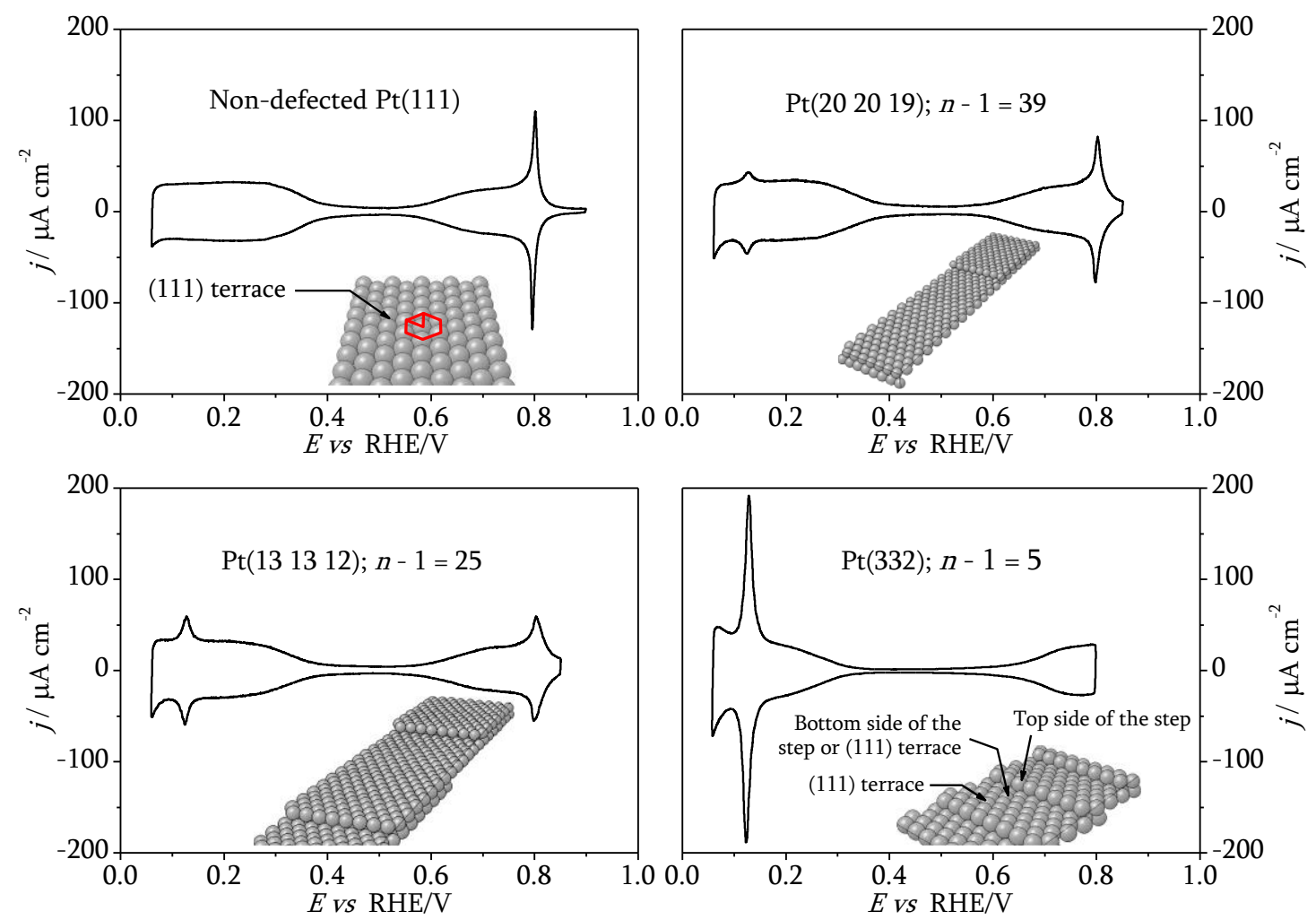

Figure 1. Cyclic voltammograms for Pt crystalline electrodes in $0.1 \mathrm{M} \mathrm{HClO}_{4}$ solution. Electrodes: non-defected $\operatorname{Pt}(111), \operatorname{Pt}(2020$ 19), $\operatorname{Pt} 1313$ 12), and $\operatorname{Pt}(332)$. The data were recorded at a temperature of $25^{\circ} \mathrm{C}$ (the same temperature as the reference electrode), at a scan rate of $50 \mathrm{mV} \mathrm{s}^{-1}$. The electrodes were annealed in a butane/air flame, followed by cooling in an $\mathrm{Ar} / \mathrm{H}_{2}$ atmosphere. The data include hard models for each crystal surface (drawn here: http://surfexp.fhi-berlin.mpg.de/). 

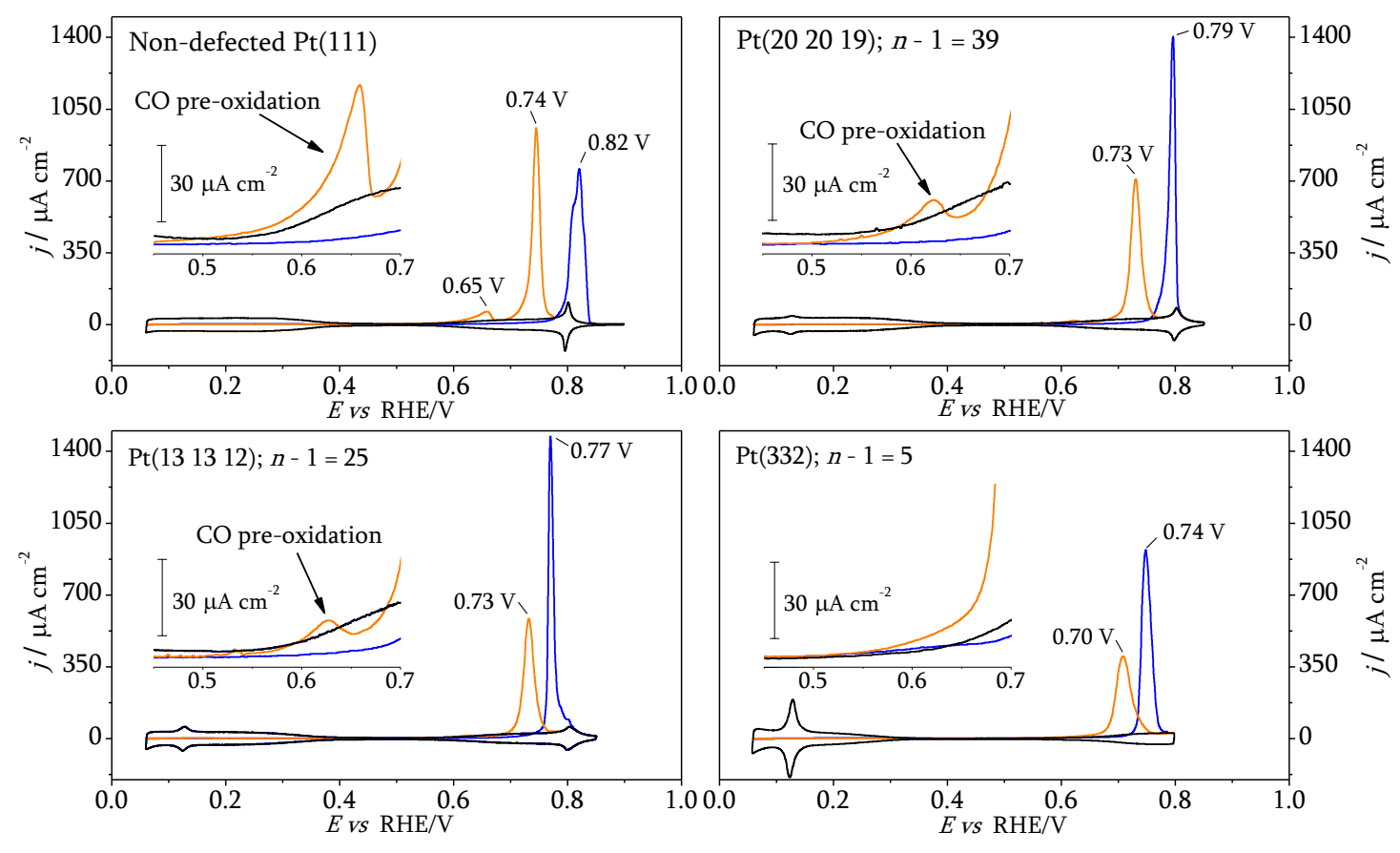

Figure 2. CO stripping on Pt crystalline electrodes in $0.1 \mathrm{M} \mathrm{HClO}_{4}$ solution: non-defected $\operatorname{Pt}(111), \operatorname{Pt}\left(2020\right.$ 19), $\operatorname{Pt}\left(1313\right.$ 12), and $\operatorname{Pt}(332)$. Orange line: the $\mathrm{CO}_{\text {ads }}$ layer was formed while the flame annealed $\mathrm{Pt}(111)$ electrode was cooled in a $\mathrm{CO}$ atmosphere. Blue line: the $\mathrm{CO}_{\mathrm{ads}}$ layer was formed at a constant potential of $0.100 \mathrm{~V}_{\text {RHE. }}$ Black line: cyclic voltammetry in 0.1 $\mathrm{M} \mathrm{HClO} 4$ solution. The inset shows magnification of the pre-oxidation zones of these voltammograms. The data were recorded at a temperature of $25^{\circ} \mathrm{C}$ (the same temperature as the reference electrode), at a scan rate of $50 \mathrm{mV} \mathrm{s}^{-1}$. 

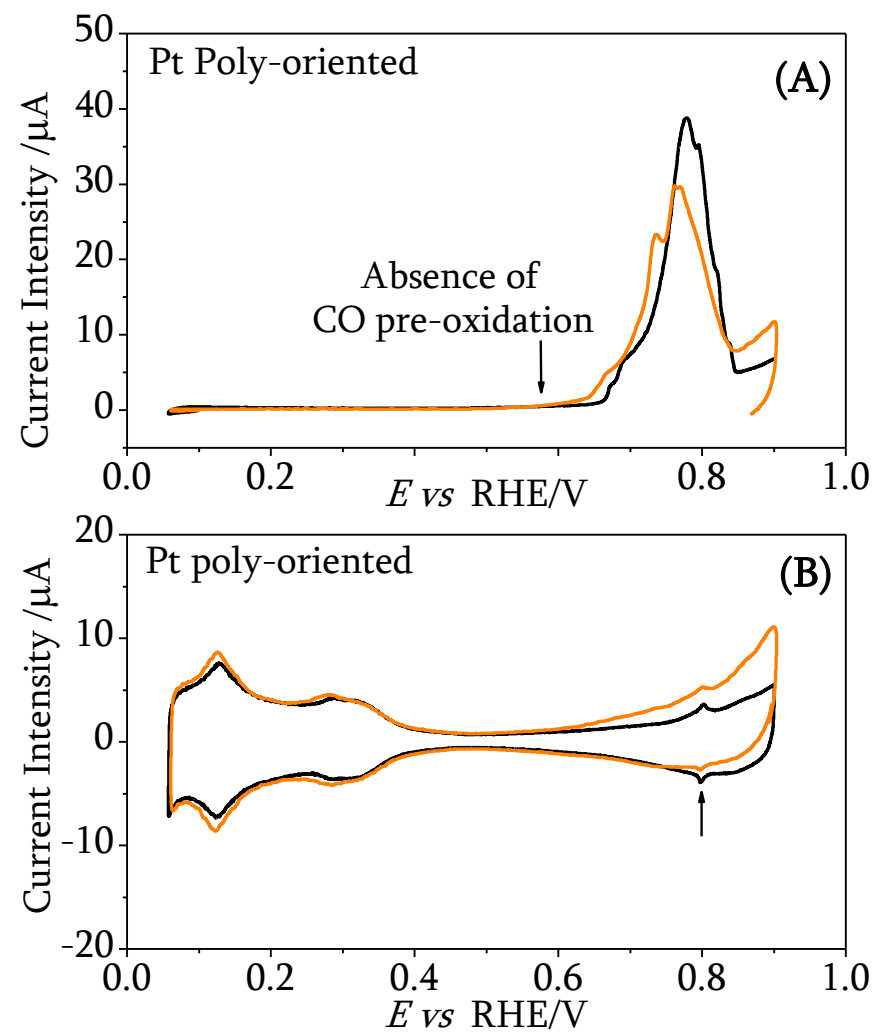

Figure 3. $\mathrm{CO}$ stripping on $\mathrm{Pt}$ poly-oriented electrode in $0.1 \mathrm{M} \mathrm{HClO}_{4}$ solution. Panel A: (orange line) $\mathrm{CO}_{\text {ads }}$ layer formed during cooling of the flame annealed $\mathrm{Pt}(111)$ electrode in a $\mathrm{CO}$ atmosphere; (black line) $\mathrm{CO}_{\text {ads }}$ layer formed at a constant potential of $0.100 \mathrm{~V}_{\text {RHE. }}$ Panel B: (black line) cyclic voltammogram of a $\mathrm{Pt}$ poly-oriented electrode cooled in an $\mathrm{Ar} / \mathrm{H}_{2}$ atmosphere; (orange line) cyclic voltammogram of a Pt poly-oriented electrode recorded after the stripping of the $\mathrm{CO}_{\text {ads }}$ layer formed during cooling of the electrode in a $\mathrm{CO}$ atmosphere. The data were recorded at a temperature of $25{ }^{\circ} \mathrm{C}$ (the same temperature as the reference electrode), at a scan rate of $50 \mathrm{mV} \mathrm{s}^{-1}$. 


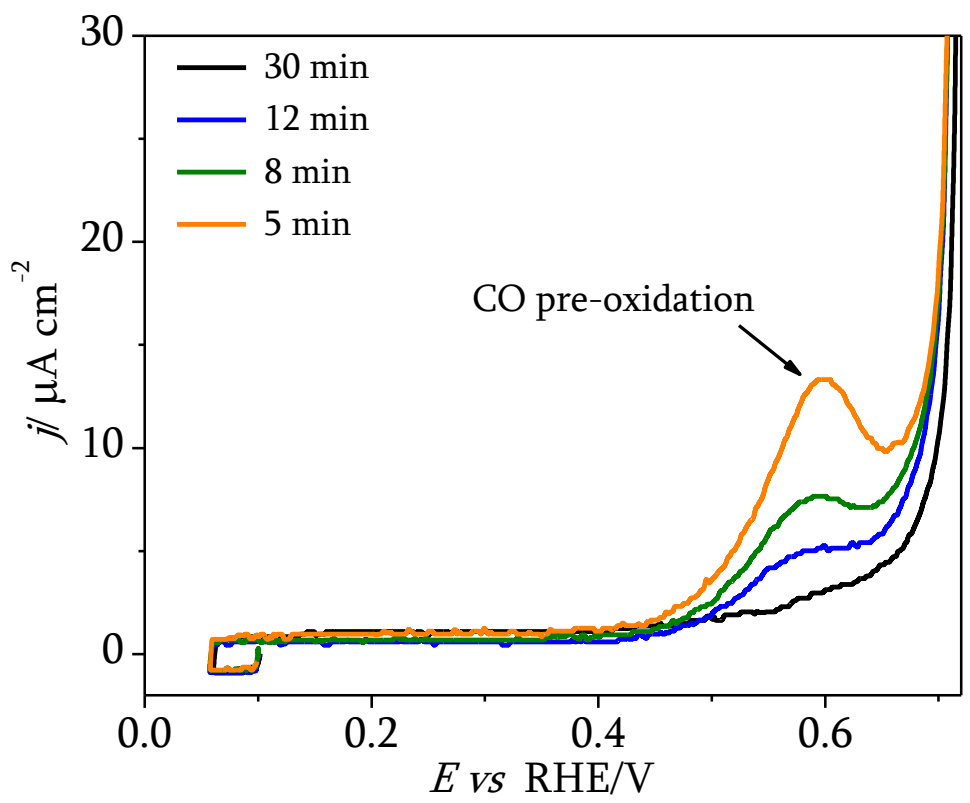

Figure 4. Importance of $\mathrm{CO}$ in the solution for evolution of the $\mathrm{CO}$ pre-oxidation on a $\mathrm{Pt}(332)$ stepped surface in $0.1 \mathrm{M} \mathrm{HClO}_{4}$ solution. The $\mathrm{CO}_{\text {ads }}$ layer was formed at a constant potential of $0.100 \mathrm{~V}_{\mathrm{RHE}}$ and non-adsorbed $\mathrm{CO}$ was removed from the solution for different times (indicated). For better visualization, the figure only shows the regions of the voltammograms corresponding to the pre-oxidation of $\mathrm{CO}$. The data were recorded at a temperature of $25{ }^{\circ} \mathrm{C}$ (the same temperature as the reference electrode), at a scan rate of $50 \mathrm{mV} \mathrm{s}^{-1}$. 


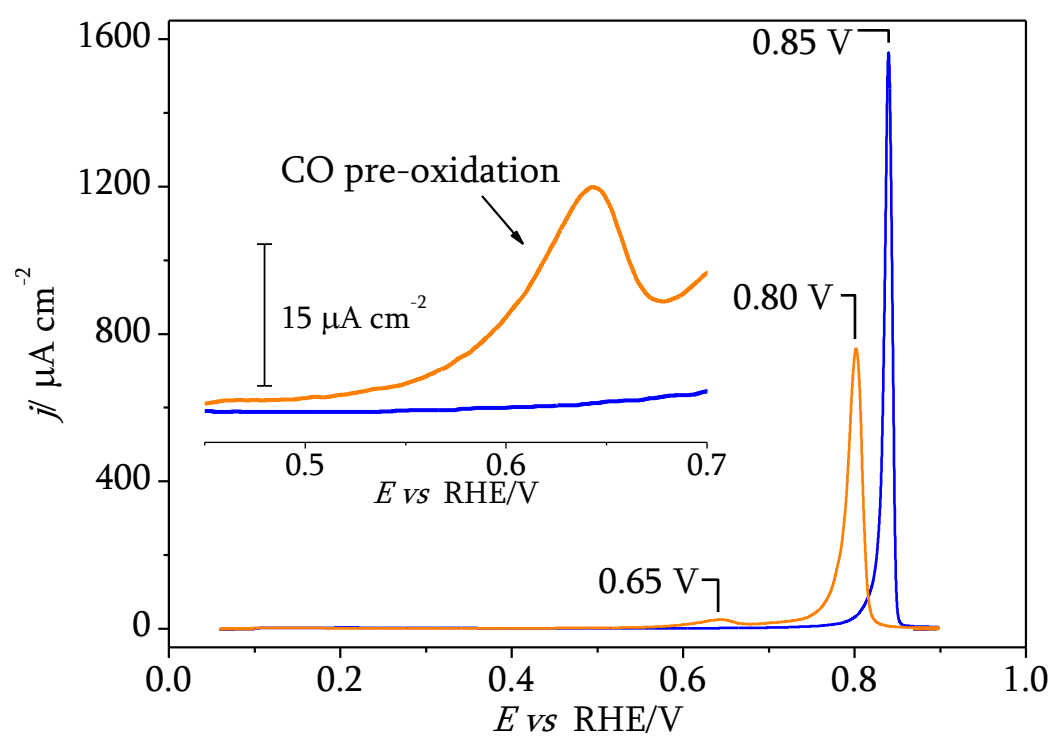

Figure 5. CO electro-oxidation on a non-defected $\mathrm{Pt}(111)$ crystal in a $0.1 \mathrm{M} \mathrm{H}_{2} \mathrm{SO}_{4}$ solution. Orange line: the $\mathrm{CO}_{\mathrm{ads}}$ layer was formed while the flame annealed $\operatorname{Pt}(111)$ electrode was cooled in a $\mathrm{CO}$ atmosphere. Blue line: the $\mathrm{CO}_{\text {ads }}$ layer was formed at a constant potential of $0.100 \mathrm{~V}$. The data were recorded at a temperature of $25{ }^{\circ} \mathrm{C}$ (the same temperature as the reference electrode), at a scan rate of $50 \mathrm{mV} \mathrm{s}^{-1}$. 


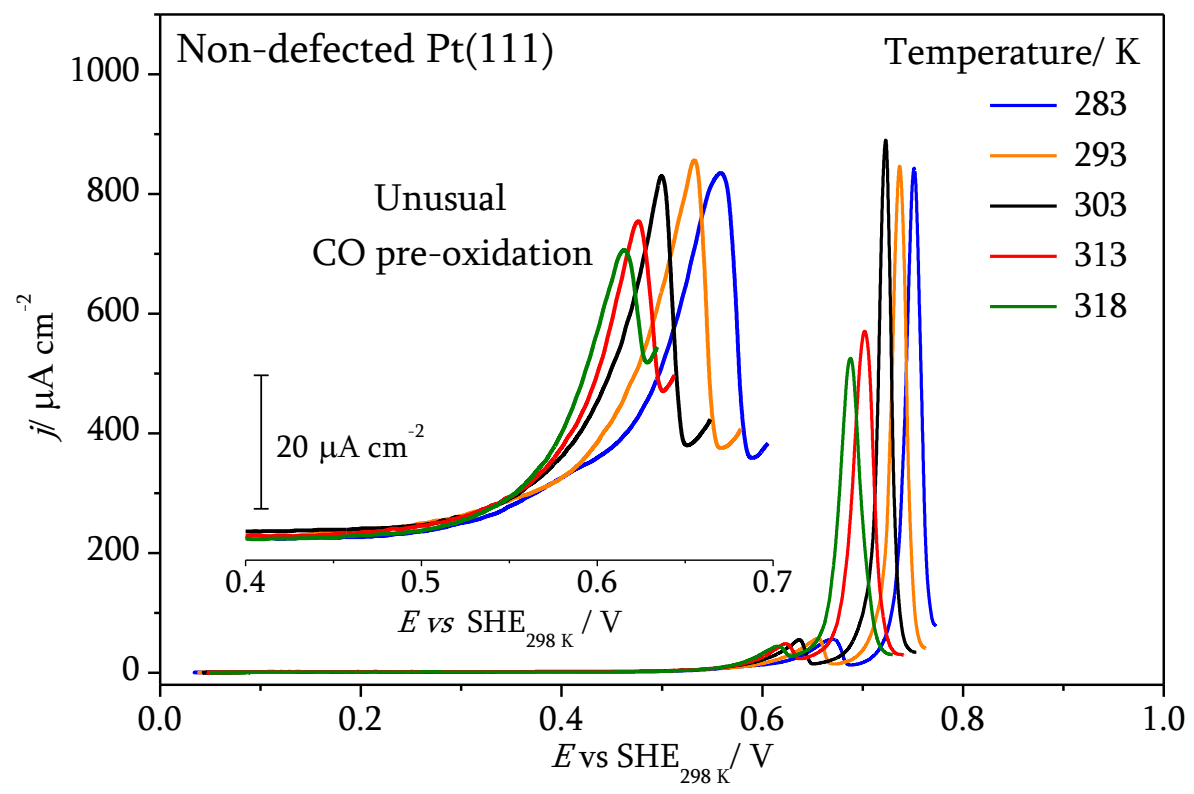

Figure 6. Influence of the temperature on the electro-oxidation of $\mathrm{CO}_{\text {ads }}$ on a non-defected $\mathrm{Pt}(111)$ electrode in $0.1 \mathrm{M} \mathrm{HClO}_{4}$ solution. The $\mathrm{CO}_{\text {ads }}$ layers were formed while the flame annealed $\mathrm{Pt}(111)$ electrode was cooled in a $\mathrm{CO}$ atmosphere. The inset shows the magnification of these voltammograms in the pre-oxidation zones. The temperature of each experiment is indicated in the figure. (The reference electrode at a temperature of $25^{\circ} \mathrm{C}$ ) Potentials on the SHE scale, at $298 \mathrm{~K}$. The scan rate applied was $50 \mathrm{mV} \mathrm{s}^{-1}$. 


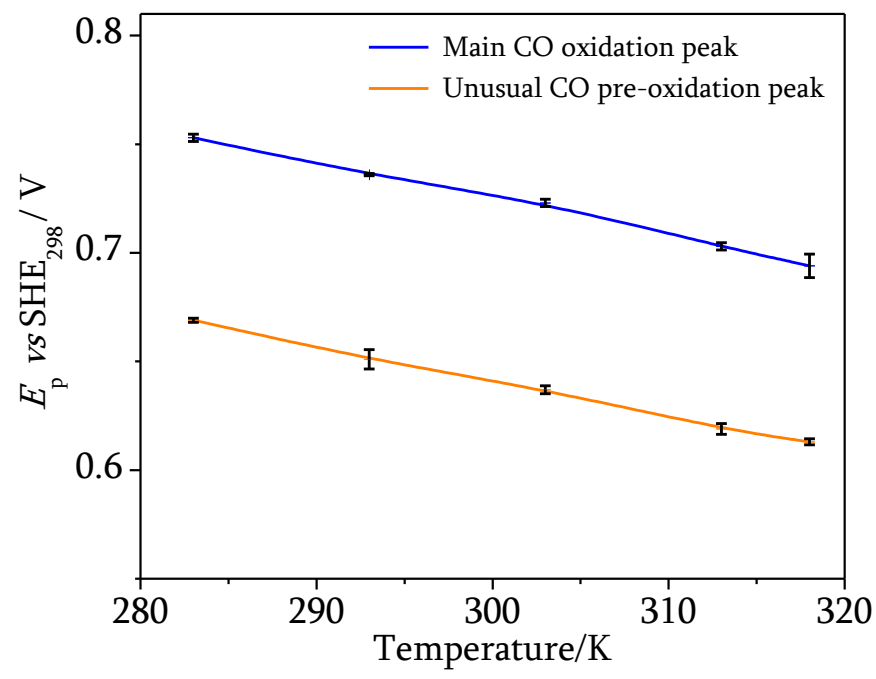

Figure 7. Plot of the peak potential (SHE scale, at $298 \mathrm{~K}$ ) against absolute temperature, for electro-oxidation of $\mathrm{CO}$ on a non-defected $\mathrm{Pt}(111)$ electrode. The data refer to Figure 6. The error bars correspond to the standard deviation for three different measurements. 

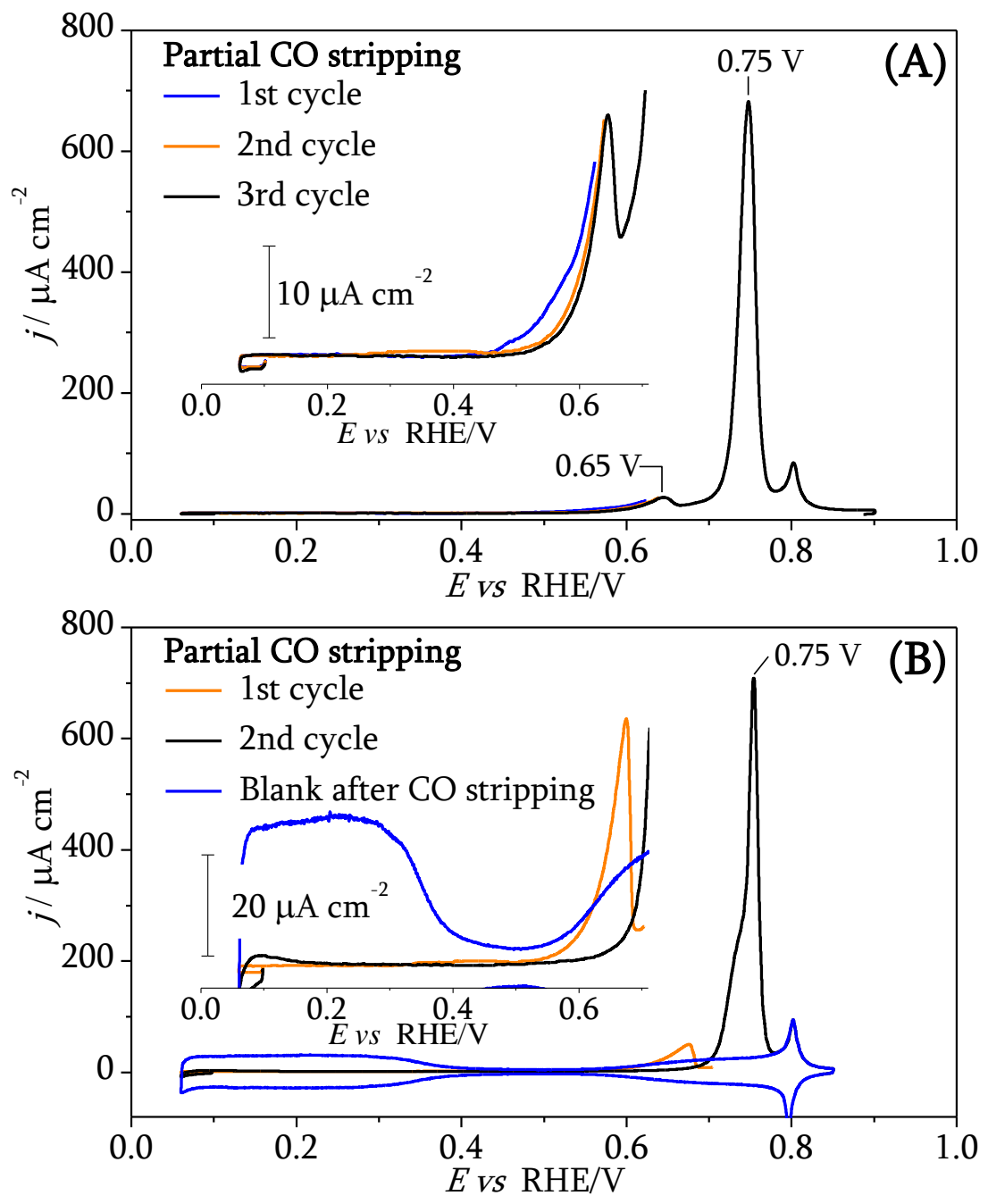

Figure 8. Partial electro-oxidative stripping of a $\mathrm{CO}_{\text {ads }}$ layer on a non-defected $\mathrm{Pt}(111)$ crystalline electrode in $0.1 \mathrm{M} \mathrm{HClO}_{4}$ solution. The $\mathrm{CO}_{\text {ads }}$ layer was formed while the flame annealed $\mathrm{Pt}(111)$ electrode was cooled in a $\mathrm{CO}$ atmosphere. (A): The CO pre-oxidation was partially removed by successive steps of partial cycles, applying different upper limits (shown by the blue, orange, and black lines). The inset shows the magnification of these voltammograms in the pre-oxidation zones. (B): The CO pre-oxidation was eliminated at once (shown by the orange line), followed by removal of the rest of the CO layer in a subsequent cycle (shown by the black line). The data include the voltammogram for the Pt single crystal after CO stripping. In both panels, the insets highlight the CO pre-oxidation regions. The data were recorded at a temperature of $25^{\circ} \mathrm{C}$ (the same temperature as the reference electrode), at a scan rate of $50 \mathrm{mV} \mathrm{s}^{-1}$. 


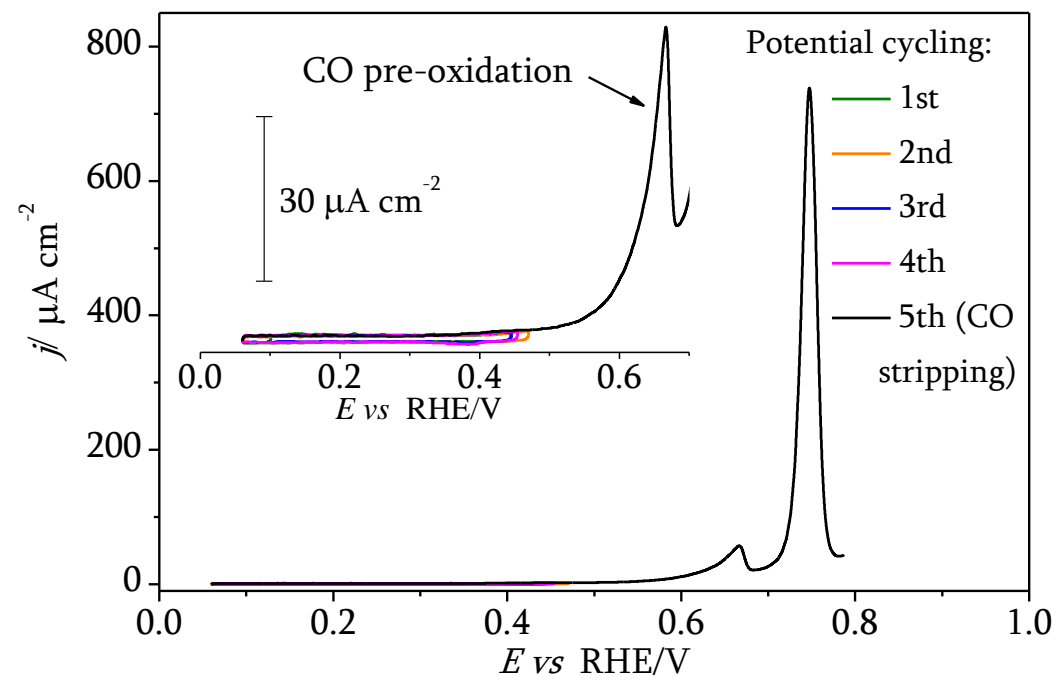

Figure 9. Electro-oxidation of a $\mathrm{CO}_{\text {ads }}$ layer on a non-defected $\mathrm{Pt}(111)$ electrode in a $0.1 \mathrm{M}$ $\mathrm{HClO}_{4}$ solution. The $\mathrm{CO}$ layer was formed during cooling of the flame annealed Pt electrode in a $\mathrm{CO}$ atmosphere. Before scanning the potential to electro-oxidize the $\mathrm{CO}$ layer, the potential was successively cycled (indicated in the figure) in the hydrogen region, as highlighted in the inset. The data were recorded at ambient temperature (about $25^{\circ} \mathrm{C}$ ). The scan rate was $50 \mathrm{mV} \mathrm{s}^{-1}$. 
TOC Graphic

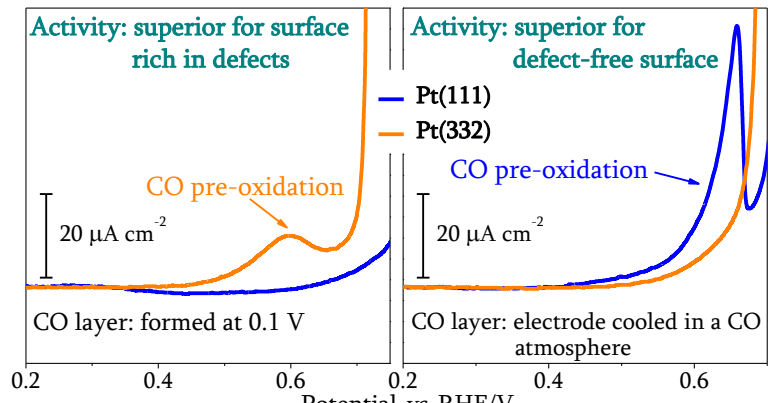

